OPEN ACCESS

Edited by:

Marina Blanco,

Duke University, United States

Reviewed by:

Daniel Hending,

University of Bristol, United Kingdom

Travis Steffens,

University of Guelph, Canada

*Correspondence: Livia Schäffler

l.schaeffler@leibniz-zfmk.de

Specialty section:

This article was submitted to

Population and Evolutionary

Dynamics,

a section of the journal

Frontiers in Ecology and Evolution

Received: 21 July 2020 Accepted: 22 February 2021

Published: 22 March 2021

Citation:

Schäffler L, Kappeler PM and Halley JM (2021) Mouse Lemurs in an Assemblage of Cheirogaleid Primates

in Menabe Central, Western

Madagascar - Three Reasons

to Coexist.

Front. Ecol. Evol. 9:585781. doi: $10.3389 /$ fevo.2021.585781

\section{Mouse Lemurs in an Assemblage of Cheirogaleid Primates in Menabe Central, Western Madagascar - Three Reasons to Coexist}

\author{
Livia Schäffler ${ }^{1,2 *}$, Peter M. Kappeler ${ }^{2}$ and John M. Halley ${ }^{3}$ \\ ${ }^{1}$ Conservation Ecology Section, Centre for Biodiversity Monitoring, Zoological Research Museum Alexander Koenig - \\ Leibniz Institute for Animal Biodiversity, Bonn, Germany, ${ }^{2}$ Behavioral Ecology and Sociobiology Unit, German Primate \\ Center - Leibniz Institute for Primate Research, Göttingen, Germany, ${ }^{3}$ Department of Biological Applications \\ and Technology, University of loannina, Ioannina, Greece
}

Ecological communities are structured by interactions between coexisting species that mutually influence their distribution and abundance. Ecologically similar species are expected to exclude one another from suitable habitat, so the coexistence of two mouse lemur species in an assemblage of several closely related cheirogaleid primates in the central Menabe region of Madagascar requires explanation. We assessed the occurrence of Madame Berthe's mouse lemurs (Microcebus berthae) and Gray mouse lemurs (Microcebus murinus), and of two larger cheirogaleids, Coquerel's giant mouse lemur (Mirza coquereli) and the western fat-tailed dwarf lemur (Cheirogaleus medius), by nocturnal line transect walks between 2003 and 2007. We explored interspecific interactions for four different scenarios with varying resource availability (degraded and non-degraded habitat in the wet and dry season), both on the regional spatial scale and on a finer local (transect) scale. We tested whether the interspecific distribution of mouse lemur individuals indicates interspecific competition and whether their regional coexistence might be stabilized by interactions with $M$. coquereli or C. medius. We developed the "Inter-Species Index of Attraction" (ISIA) to quantify the observed interspecific interactions within transects and determined if these were significantly different from a null model generated by a combination of randomization and bootstrapping to control for intraspecific aggregation. For the two mouse lemurs, interspecific spatial exclusion was most pronounced during the resource-poor dry season, consistent with the hypothesis of feeding competition. Seasonally varying distribution patterns indicated resource tracking in a spatio-temporally heterogeneous environment. The interspecific distribution of individuals suggested that the larger cheirogaleids benefit $M$. berthae at the expense of the more abundant $M$. murinus: spatial associations of both, $M$. coquereli and $C$. medius, with $M$. murinus were negative in most scenarios and across spatial scales, but neutral or even positive with $M$. berthae. 
Thus, our study revealed that coexistence among ecologically similar heterospecifics can rely on complex density-mediated interspecific processes varying with habitat quality and season. With regard to the stability of animal assemblages, this insight has major implications for biodiversity conservation.

Keywords: ecological structure, community ecology, interspecific coexistence, competitive exclusion, intraguild predation, lemurs, dry deciduous forest, western Madagascar

\section{INTRODUCTION}

The ecological structure of communities is determined by a combination of abiotic and biotic factors (Polis, 1994; Stokstad, 2009). Complex relationships between consumers and resources affect food web dynamics both "top-down" and "bottom-up" (Polis and Strong, 1996; Leibold et al., 1997). Interspecific interactions between and within trophic levels structure ecological communities (Diamond, 1975) either directly between species (Lawton and Hassell, 1981) or indirectly (Strauss, 1991) if pairwise interactions are influenced by a third species (Bonsall and Hassell, 1997). According to the competitive exclusion principle, a pair of species with identical ecological demands cannot coexist (Hardin, 1960). Even if there is no universal limit to the similarity of competing species (Abrams, 1983), congeneric species should be engaged in intense competition (Sfenthourakis et al., 2006) and their coexistence in taxonomic assemblages (sensu Pianka, 1973) requires explanation.

Several mechanisms can stabilize the coexistence of closely related species with similar ecological demands (Chesson, 2000b), with the following being most relevant to our study. First, heterogeneity of the environment and differential responses of species to this variability facilitates coexistence (Levin, 1992). Competitive superiority of a species in certain habitat types may lead to local exclusion of inferior competitors, but coexistence can still be favored on a regional scale if spatiotemporal heterogeneity provides the outcompeted species with refuges (Amarasekare, 2003; López-Gómez and Molina-Meyer, 2006). Second, indirect interactions in species assemblages may weaken the intensity of direct interactions such as competition, and thus stabilize coexistence (Glasser, 1979; Holt, 1984; Ashehoug and Callaway, 2015).

Predation-risk may influence the decision of animals to avoid high-risk areas, which may have benefits for other community members (Willems and Hill, 2009; Bidner, 2014). If a predator favors the competitively superior species, either via specific preference or density dependence (Holt and Lawton, 1994; Chesson, 2000b), it reduces the relative abundance of the preferred prey (Sundell et al., 2003). This may indirectly benefit the competitively inferior prey species and prevent interspecific exclusion in assemblages of resource-limited consumers (Paine, 1966; Caswell, 1978; McPeek, 2014). Such changes of the competitive landscape ("keystone predation": Paine, 1969) can have strong consequences for species richness (Walsh, 2013; Bidner, 2014). Shared natural enemies may lead to competition among prey for enemy-free space, generating spatial patterns resembling those of direct competition ("apparent competition":
Holt, 1977; Bonsall and Holt, 2003). Two species with dietary niche overlap and shared predation risk may outcompete each other in different tasks and spatially segregate into most productive habitats and predator-free space (Chesson, 2000a,b). Finally, if predator and prey belong to the same trophic guild, they may simultaneously affect each other by both direct competition and predation ("intraguild predation": Polis et al., 1989; Polis and Holt, 1992; Holt and Polis, 1997).

Global patterns of species co-occurrence suggest that primate communities are not randomly structured (Bourlière, 1985; Kamilar, 2009). Primary productivity and interspecific competition have been the major foci in primate community ecology (Schreier et al., 2009; Kamilar and Ledogar, 2011), whereas the effects of predation remain largely neglected (Bidner, 2014). Positive interactions among other terrestrial vertebrates have long been recognized (Terborgh, 1990; Dickman, 1992; Stensland et al., 2003) but remain underacknowledged as determinants of species co-occurrence (Stachowicz, 2001; Bruno et al., 2003; Denis et al., 2019). Studies on costs and benefits of mixed-species associations in primates are numerous, but they largely focused on large-bodied, diurnal, and gregarious haplorrhines (e.g., Heymann and Buchanan-Smith, 2000; Buzzard, 2010; Singh et al., 2011). Thus, additional studies from different primate lineages, in particular strepsirrhines, are needed to test the above-mentioned predictions about community composition and stability.

Lemurs make up about $20 \%$ of the global primate species richness (Estrada et al., 2017) and represent more than $60 \%$ of mammalian genera in Madagascar (Ganzhorn, 1999). Interspecific competition in lemurs is therefore likely strong (Kamilar and Guidi, 2010; Beaudrot and Marshall, 2011). The non-random checkerboard distribution of frugivore-insectivore (omnivore) lemur species in western Madagascar indeed suggests high levels of interspecific competition for food (Kamilar and Ledogar, 2011). However, based on differences in lemur body size and dietary niches, Schreier et al. (2009) challenged the assumption of a high number of competing species pairs in Madagascar and called for studies comparing simulated distribution patterns with observed community structure to highlight species competing within assemblages. A majority of studies that have investigated habitat utilization and feeding habits of co-occurring lemur species to date were conducted on single study sites (e.g., Rendigs et al., 2003; Schwab and Ganzhorn, 2004; Dammhahn and Kappeler, 2008a,b, 2014; Rakotondravony and Radespiel, 2009; Rakotondranary and Ganzhorn, 2012). We therefore aim at examining the interspecific spatial distribution in a community of nocturnal lemurs throughout the entire area of coexistence. 
A taxonomic assemblage of four closely related lemur species of the cheirogaleid family (Lemuriformes: Cheirogaleidae) affords opportunity to study spatial consequences of interspecific interactions: the mouse lemurs Microcebus berthae and Microcebus murinus, the closely related giant mouse lemur Mirza coquereli and dwarf lemur Cheirogaleus medius are nocturnal, arboreal, and relatively small primates endemic to Madagascar (average adult masses of $31 \mathrm{~g}$ in $M$. berthae and $60 \mathrm{~g}$ in M. murinus: Schmid and Kappeler, 1994; Rasoloarison et al., 2000, $120 \mathrm{~g}$ in C. medius: Fietz, 2003, and $250 \mathrm{~g}$ in M. coquereli: Kappeler, 2003). These cheirogaleid species occur sympatrically in the dry forest of the central Menabe region in western Madagascar that is subject to both, spatial and temporal heterogeneities.

The restricted biogeographic range of $M$. berthae is confined to Menabe Central (Rasoloarison et al., 2000; Schwab and Ganzhorn, 2004), and its low disturbance tolerance indicate ecological specialization (Schäffler, 2012; Schäffler and Kappeler, 2014a). Its sympatric congener M. murinus, in contrast, is found throughout western and southern Madagascar and regionally cooccurs with several other mouse lemur species (Weisrock et al., 2010). The wide biogeographic distribution of $M$. murinus was explained by its high competitive potential, seasonal plasticity in feeding habits, efficient energy-saving strategies, and behavioral flexibility in habitat selection (Radespiel, 2016). In western Madagascar, M. murinus inhabits degraded forest parts and even village environments (Ganzhorn, 1987; Dammhahn and Kappeler, 2008a; Schäffler, 2012; Schäffler et al., 2015). Mouse lemurs are omnivorous (or more specifically fauni-frugivorous: Steffens and Lehman, 2016) but the feeding niche of $M$. berthae is narrower than that of $M$. murinus (Dammhahn and Kappeler, 2008a, 2010). To cope with seasonal fluctuations in food supply (Schwab and Ganzhorn, 2004) mouse lemurs rely on sugary secretions of homopteran larvae (genus Flatidia) as a key fallback food (Dammhahn and Kappeler, 2008a). Increased home range sizes of females in areas of co-occurrence indicated interspecific competition on a local scale (Dammhahn and Kappeler, 2009) and negative interspecific association patterns of populations were also observed on a regional scale (Schäffler et al., 2015).

The mouse lemurs are likely also engaged in interspecific interactions with the other two sympatric cheirogaleids (Hladik et al., 1980; Lahann, 2008). Stable isotope analyses of the cheirogaleid species in Menabe Central suggested that interspecific competition determined ecological structure in this species assemblage (Dammhahn and Kappeler, 2014). In Menabe Central, $M$. coquereli occurs in relatively low population densities and is heterogeneously distributed whereas C. medius was found in higher numbers in intact habitat than in degraded forest parts (Schäffler and Kappeler, 2014b). Opportunistic (intraguild) predation by $M$. coquereli was observed on M. murinus (Rakotonirainy, 2003; Schliehe-Diecks et al., 2010) but remains un-reported on $M$. berthae. Corresponding negative associations of $M$. coquereli and $M$. murinus and spatial overlaps between $M$. coquereli and $M$. berthae were documented at the population level (Schäffler et al., 2015). While C. medius hibernates throughout the dry season (Dausmann et al., 2004), M. murinus females enter daily and/or prolonged torpor to save energy (Schmid, 1998, 2000, 2001). Microcebus murinus and C. medius compete for tree holes used for resting and breeding (Ganzhorn and Schmid, 1998; Kappeler and Rasoloarison, 2003) and there is evidence for feeding niche overlap in south-eastern Madagascar (Lahann, 2007). In contrast, M. berthae is active throughout the dry season (Schmid and Kappeler, 2005) and rests in open vegetation (Dammhahn and Kappeler, 2005). In a small-scale study, C. medius was found to partially displace M. murinus, whereas positive spatial associations with $M$. berthae indicated relaxed competition (Schwab and Ganzhorn, 2004).

Ecological patterns emerge from biological mechanisms that operate at different scales: the structure of communities may be imposed by large scale constraints but decisions to spatially avoid or associate with a co-occurring species are made by individuals responding to variations in intra- and interspecific densities (Levin, 1992). In lemurs, competitor and predator recognition is based on acoustic, visual, and olfactory cues: far-reaching acoustic signals and long-lasting odors enable recognition of other individuals over greater distances and longer timespans than visual cues, and olfactory signals are of particular importance to nocturnal arboreal lemurs under poor visibility (Klopfer, 1977). Thus, mouse lemur communication by acoustic and olfactory signals (Braune et al., 2005) should facilitate interspecific recognition. They can also be assumed to recognize other cheirogaleids not only in their immediate vicinity: $M$. coquereli is easily detectable by a variety of vocalizations, and olfactory signals likely facilitating its recognition as a potential predator (Kappeler, 2003). Microcebus spp. were shown to respond to olfactory cues of mammalian predators, presumably based on metabolites of meat digestion (Deppe et al., 2007; Sündermann et al., 2008; Kappel et al., 2011; Deppe and Kushnick, 2020). Cheirogaleus medius can be recognized by mouse lemurs by its frequent olfactory markings of territorial borders (Fietz, 1999b).

In this study, we aimed at further elucidating determinants of ecological structure in this cheirogaleid species assemblage by linking patterns observed at the population level (Schäffler et al., 2015) to the distribution of individuals. The hypothesized coexistence-stabilizing mechanism operates on the local scale (Huston, 1999), so the interspecific distribution of individuals should reflect competitive or predator-prey interactions. We investigated the distribution of cheirogaleid individuals across spatio-temporal heterogeneities to scrutinize if and under which constraints co-occurring dwarf and giant mouse lemurs may stabilize competitive mouse lemur coexistence. Against this background, we examine the following questions and hypotheses:

1. Do interspecific spatial distributions of individuals reflect competition between the two mouse lemur species? If there is intense competition between $M$. murinus and M. berthae, as indicated by previous small-scale studies (Schwab and Ganzhorn, 2004; Dammhahn and Kappeler, 2008a,b, 2009, 2010), we expect to observe strong spatial exclusion between these two species (H1a). Interspecific distribution patterns of individuals do not allow for conclusions about the direction of spatial displacement, but evidence from different regions in Madagascar suggests that $M$. murinus has a higher competitive potential than its sympatric sister species (Dammhahn and Kappeler, 2008b; 
Rakotondranary et al., 2011; Thorén et al., 2011a). If competition is for food, interspecific avoidance should be most pronounced under resource scarcity, i.e., during the dry season (H1b) and in degraded habitat (H1c).

2. Does intraguild predation by $M$. coquereli on $M$. murinus stabilize competitive coexistence between the two mouse lemur species? If (intraguild) predation creates refuges for $M$. berthae from competition with its congener as interpreted based on the interspecific distribution of cheirogaleid populations observed in non-degraded habitat during the dry season (Schäffler et al., 2015), spatial avoidance of $M$. coquereli by $M$. murinus should be reflected in the distribution of individuals. As giant mouse lemur predation on mouse lemurs has only been reported on M. murinus (Schliehe-Diecks et al., 2010), we expect strong spatial exclusion between this species and M. coquereli (H2a), but not between $M$. berthae and $M$. coquereli (H1b). Negative spatial association of $M$. coquereli and $M$. murinus individuals should be particularly pronounced during the dry season when resource scarcity ought to favor opportunistic predation ( $\mathrm{H} 2 \mathrm{c})$.

3. Does C. medius stabilize competitive mouse lemur coexistence by spatial exclusion of $M$. murinus? Partial displacement of $M$. murinus, but not $M$. berthae, suggested that $M$. berthae would develop large subpopulations where C. medius reduces habitat suitability for M. murinus (Schwab and Ganzhorn, 2004). This hypothesis was not supported by the distribution of mouse lemur populations in relation to the occurrence of $C$. medius (Schäffler et al., 2015) but may still be reflected by the distribution individuals across spatio-temporal heterogeneities. Therefore, we predict a negative association between $C$. medius and $M$. murinus (H3a) but not between $C$. medius and $M$. berthae (H3b). Spatial consequences of competition between $M$. murinus and $C$. medius should be strongest when resources are scarce $(\mathrm{H} 3 \mathrm{c})$. With respect to food, spatial avoidance would be expected predominately in degraded habitat. Competition for tree holes should be more pronounced in non-degraded habitat with more old-growth trees and high C. medius population densities.

\section{MATERIALS AND METHODS}

\section{Study Site}

The region of Menabe Central ranges from the Mozambique Channel to the bottom of the central highlands and is bound by the rivers Tsiribihina to the north and Morondava to the south. With approximately 65,000 hectares of forested area at the time of our surveys, Menabe Central retained the largest remnant of dry deciduous forest in western Madagascar (Sorg et al., 2003). Varying levels of anthropogenic pressure fragmented the forest and resulted in a mosaic of different vegetation forms between and within major fragments (Smith et al., 1997; see also Figure 4 in Online Resource 2). The climate is classified as tropical dry with a distinct dry season between March and November and a hot wet season with heavy rains peaking from December to February (Sorg and Rohner, 1996). Slash and burn agriculture and illegal logging are continuously degrading the forest in Menabe Central. The northernmost forest part
Ambadira still contained considerable areas of near primary forest with moderate anthropogenic disturbance levels (Smith et al., 1997). In Kirindy Forest further south, exploitation has been limited by a silvicultural concession (Ganzhorn et al., 1990) and the research station of the German Primate Center (Sorg et al., 2003). Largely unrestricted forest utilization in other parts of Menabe Central have segregated Ambadira and Kirindy and the narrow corridor connecting them is highly frequented by rural people. The southernmost forest part in the Reserve Spécial Andranomena has been prone to clearing and degradation for decades despite governmental protection (Smith et al., 1997; Randrianandianina et al., 2003).

\section{Line Transect Sampling}

We sampled sites across the area of occurrence of the four cheirogaleid species in the Menabe Central region in western Madagascar (boundaries north $44^{\circ} 37^{\prime} \mathrm{E}, 19^{\circ} 44^{\prime} \mathrm{S}$; south $20^{\circ} 13^{\prime} \mathrm{S}$, $\left.44^{\circ} 38^{\prime} \mathrm{E}\right)$. To account for temporal heterogeneity, we conducted surveys during both the warm and resource-rich wet season and the cooler dry season (Sorg et al., 2003). We distributed 34 line transects of $1 \mathrm{~km}$ length as randomly as possible in the dense dry deciduous forest and categorized the habitat they were in as either non-degraded or degraded (for details on sampling design and habitat assessment, see Schäffler et al., 2015 and Supplementary Figure 4).

We surveyed cheirogaleid species by repeated transect walks over four dry seasons ( 3 months, respectively, between July and September in 2003, 2004, 2006, and 2007) and two wet season surveys (February to April and November to December in 2007). During each survey, cheirogaleid occurrence was determined on 13-23 of the $1 \mathrm{~km}$ line transects by distance sampling (Buckland et al., 2001, 2010). The majority of 34 dry-season and 26 wetseason line transects were walked twice or three times over subsequent surveys, amounting to a total of 127 transect walks of $1 \mathrm{~km}$. Two observers trained to recognize cheirogaleids in their natural habitat at night walked with headlights along the line transects at a standardized pace of about $1 \mathrm{~km} / \mathrm{h}$ between 6:00 pm and 8:30 pm. Using torches and binoculars, individuals were visually detected and identified to the species level. While $C$. medius and $M$. coquereli are relatively easy to recognize, also at greater distances, distinction of the two mouse lemur species requires skilled eyes. Both observers were trained in discriminating $M$. berthae from $M$. murinus by its considerably smaller size and longer tail, as well as its more gracile body and facial shape with shorter ears (Schmid and Kappeler, 1994). Individuals located too far from the transect line for reliable identification were approached by the observers. Animals that could not be identified with confidence were excluded from subsequent analyses. Of the 786 Microcebus sightings, 92 were M. berthae (11,7\%), 514 M. murinus $(65,4 \%)$, and 180 individuals could not be identified to species level $(22,9 \%)$. The perpendicular distance of detected animals from the transect line was estimated by both observers independently to warrant reliability (Buckland et al., 2001); if no agreement was reached, we measured the distance by step length. Laser range finders were of limited use in the forest, particularly during the wet season with dense foliage. The number of detections declined with increasing distance 
from the transect line in the same way for identified and nonidentified Microcebus individuals. Positions along transects were determined with a Garmin GPSmap 60CSx device providing high positioning accuracy under a closed canopy and controlled by flags fixed on trees every $25 \mathrm{~m}$.

\section{Analysis of the Interspecific Distribution of Individuals}

The analysis in this paper is designed to investigate the associations between different pairs of species at two different scales. On the coarse or "regional" scale, we considered the simple correlations between counts of individuals from different species across the array of transect walks on the basis of Spearman's rank correlation. For the finer or "local" scale, we considered the aggregation or segregation between individuals within transects, using an "Inter-Species Index of Attraction" (ISIA). A flow chart showing the statistical analyses is given in Online Resource 1.

\section{Regional Scale Calculation}

We worked with the array of samples from the 127 transect walks. As some of these walks were conducted on the same transect, either in the same or in different years, we assumed that these repeated walks yielded independent observations (i.e., no temporal autocorrelation) and was dependent only on the time of year (i.e., dry or wet season). Our basic data were thus an array of observed individuals, including the observation number, walk number, scenario type (wet and dry season, degraded and non-degraded habitat), distance along transect, perpendicular distance from transect line and the species. This array was stored as an $\mathrm{R}$ data frame prior to running our analyses. Counting numbers of each species per transect walk yielded a matrix of observations of size $4 \times 127$ observations. We then calculated Spearman's rank correlation coefficient for each pair of species over the array of transects. Although there are six possible heterospecific pairings, only five involve mouse lemurs. Spearman's rank correlation coefficient ranges between -1 and +1 , with a negative value indicating avoidance between two species and a positive value indicating attraction. Because it is a non-parametric statistic it is attractive in being robust against departures from statistical normality. We refer to this scale as "regional," since each datum consists of the numbers of individuals for each species in each transect. This measures the possibly uneven occupation of different transects by different species on scales from $1 \mathrm{~km}$ (the length of a transect) to $13 \mathrm{~m}$ (transect width: Schäffler, 2012). The calculation of the Spearman coefficient and its $p$-value was carried out using "rcorr" function in the Hmisc package (Harrell and Dupont, 2020) in R (R Development Core Team, 2018).

\section{Local Scale Calculation}

We sought pairings of individuals by testing if they fell within the "recognition distance." An encounter situation, or interaction, between two individuals is assumed to potentially occur when the distance separating them is less than this recognition distance. To our knowledge, recognition distances of cheirogaleids have not been previously investigated in detail although the general idea appears in various studies (Lima and Dill, 1990;
Hutchinson and Waser, 2007; Jackson and Fahrig, 2012). Our choice of $150 \mathrm{~m}$ as a recognition distance was based on the notion that this distance should be the same order as home range size. Because home range estimates for cheirogaleids vary with different methods of data collection and analysis (Sterling et al., 2000), range sizes are very variable both between and within species. We chose a value of $150 \mathrm{~m}$ that is close to the median home range diameter found in previous studies (Table 1). We were interested in patterns showing possible interactions between individuals of the same or of different species. For example, competitors should avoid each other, forming fewer pairs than expected by chance. In each transect, an observation of a lemur consisted of the species identity and its location. The census of pairings for a single individual included all pairings with heterospecifics and with conspecifics when the direct (Euclidian) distance of separation was less than the recognition distance of $150 \mathrm{~m}$. There were four types of intraspecific pairings and six types of interspecific pairings. The census for the transect was the sum of distinct pairings summed over all individuals on the transect.

Having identified all pairs within the "recognition distance" on each transect walk, we pooled all results for each type of scenario. This yielded a second array consisting of observed pair numbers, scenario type and the two species identities. To calculate the correlation between any two species, "A" and "B," we then used the following "Inter-Species Index of Attraction" index (ISIA, see Online Resource 1):

$$
T(A, B)=1-\left(\sqrt{\frac{M_{A A}}{M_{0}}}+\sqrt{\frac{M_{B B}}{M_{0}}}\right)^{2}
$$

Here $M_{0}$ is the total number of pairs involving species $A$ and $B$ only, while $M_{A A}$ is the number of pairs involving two individuals both of species $A$, and $M_{B B}$ is the number of pairs involving two individuals of species $B$. The index $T(A, B)$ is a measure of the degree on interspecific attraction between $A$ and

TABLE 1 | Range of mean or median home range size estimates of both males and females in the focal cheirogaleid species as reported in the literature and corresponding diameter ranges.

\begin{tabular}{|c|c|c|c|c|}
\hline Species & $\begin{array}{l}\text { Home range } \\
\text { size [ha] }\end{array}$ & $\begin{array}{l}\text { Home range } \\
\text { diameter }[\mathrm{m}]\end{array}$ & $\begin{array}{c}\text { Mean } \\
\text { diameter }[\mathrm{m}]\end{array}$ & References \\
\hline M. murinus & $0.26-4.90$ & $51.0-221.4$ & 136.2 & $\begin{array}{l}\text { Radespiel, 2000; } \\
\text { Eberle and } \\
\text { Kappeler, 2002, } \\
\text { 2004; } \\
\text { Dammhahn and } \\
\text { Kappeler, } 2009\end{array}$ \\
\hline M. berthae & $2.04-4.92$ & $142.8-221.8$ & 182.3 & $\begin{array}{c}\text { Dammhahn and } \\
\text { Kappeler, 2005, } \\
2009\end{array}$ \\
\hline C. medius & $1.40-3.93$ & 118.3-198.2 & 158.3 & $\begin{array}{c}\text { Fietz, 1999a,b, } \\
2003\end{array}$ \\
\hline M. coquereli & $1.00-4.00$ & 100.0-200.0 & 150.0 & $\begin{array}{c}\text { Kappeler, } 1997, \\
2003^{\circ}\end{array}$ \\
\hline
\end{tabular}

Increased male home range size during the mating season not considered. 
TABLE 2 | (A) Numbers of detected cheirogaleid individuals in the four scenarios.

\begin{tabular}{|c|c|c|c|c|c|c|c|c|}
\hline & \multicolumn{2}{|c|}{ Microcebus berthae } & \multicolumn{2}{|c|}{ Microcebus murinus } & \multicolumn{2}{|c|}{ Mirza coquereli } & \multicolumn{2}{|c|}{ Cheirogaleus medius } \\
\hline & Dry season & Wet season & Dry season & Wet season & Dry season & Wet season & Dry season & Wet season \\
\hline Non-degraded habitat & 34 & 34 & 103 & 112 & 16 & 13 & - & 109 \\
\hline Degraded habitat & 19 & 4 & 187 & 72 & 14 & 24 & _- & 54 \\
\hline
\end{tabular}

(B) Comparison of cheirogaleid detections between transects sampled twice, at the onset and at the end of the rainy season (Wilcoxon signed-rank test, $n=16)$.

\begin{tabular}{|c|c|c|}
\hline Species & $z$ & $P$ (two-sided) \\
\hline M. berthae & $-0.282^{a}$ & 0.778 \\
\hline M. murinus & $-1.649^{a}$ & 0.099 \\
\hline M. coquereli & $-0.213^{a}$ & 0.832 \\
\hline C. medius & $-0.747^{b}$ & 0.455 \\
\hline
\end{tabular}

${ }^{a}$ Based on positive ranks.

${ }^{b}$ Based on negative ranks.

$B$, relative to the expected value for purely random behavior. $T$ is large when a transect has many interspecific pairs and few conspecific pairs. It has a minimum of $T=-1$ (avoidance) when $\mathrm{M}_{A A}=\mathrm{M}_{B B}=\mathrm{M}_{0} / 2$ while it has a maximum of $T=+1$ when $\mathrm{M}_{A A}=\mathrm{M}_{B B}=0$ (attraction). For each of the five mouselemur interactions, we evaluated $T(A, B)$ for every transect walk that contained at least one individual of species $A$ and $B$. Thus, for each of the five combinations, we obtained a single value of the index. While this statistic is a measure of aggregation or avoidance between two species, estimating the significance of this value requires a comparison with the distribution of values in a null model. Thus, for each of the five combinations, we compared the observed value of ISIA with values it takes in a randomized model.

To test the significance of $T$ (avoidance or attraction) we created a null model by a combination of randomization and bootstrapping, assuming that there are no interspecific interactions. Such null models have been generated by various methods (Ulrich and Gotelli, 2010). In this study, we used an approach similar to the "ideal gas model" (IGM: Hutchinson and Waser, 2007). As we aimed specifically to measure attraction or repulsion between individuals of different species, the null distribution should preserve overall levels of clustering but be neutral with respect to species. Randomization by retaining all observations in space and only shuffling species identities, however, fails to account for interspecific differences in long-range visibility. To solve this issue, we treated distances along transects (x-distances) and perpendicular distances (y-distances) separately. For any given walk, a random resample of $\mathrm{x}$-distances was found by shuffling species identities randomly among the observed positions on that walk. All the $\mathrm{y}$-distances were pooled for each species to provide a distribution of perpendicular distances. Random sampling from this distribution with replacement, as in the bootstrap method, provided the corresponding y-distances (see Online Resource 1 for details on the null model). Repeating the randomization $K$ times yields $K$ values of $T$. This method is sensitive to avoidance or aggregation between species within walks and can detect segregation at a very local scale even when there is some aggregation (e.g., because of shared habitat preferences) common to all species.
To exclude a potential bias caused by the emergence of juveniles at the end of the breeding season or by detectability varying for behavioral reasons between the onset and the end of the wet season, we compared the number of detected individuals between 16 transects sampled during both, early and late rainy season using a Wilcoxon signed-rank test. Variations in resource supply between the dry and the wet season are self-explaining. Disturbed forests differ in abiotic and biotic characteristics from intact habitats and lemurs show divergent responses in microhabitat selection (Ganzhorn et al., 1997; Ganzhorn and Schmid, 1998; Lehman et al., 2006a,b,c; Burke and Lehman, 2014; Lehman, 2016; Andriatsitohaina et al., 2020), so habitat degradation should indirectly affect species interactions. Thus, we divided the data into four "scenarios": (1) dry season - nondegraded habitat, (2) dry - degraded, (3) wet - non-degraded, and (4) wet - degraded. All calculations were repeated on these four datasets to see if the correlations changed between seasons and habitat types and were carried out in R.

\section{RESULTS}

We observed a total of 794 lemurs over the entire survey period. The most common species in both seasons was M. murinus, with 473 individuals. This is much greater than for M. berthae with 91 or $M$. coquereli with 67 total observations. In the wet season, $C$. medius was the second most common species with 163 observations. In non-degraded forest parts of Menabe Central, trees grew taller and in higher densities with a more closed canopy cover than in degraded habitat (Schäffler et al., 2015). More lemurs were observed in non-degraded habitats $(n=421)$ than in degraded habitats $(n=373)$. Numbers of detected individuals per species did vary with spatio-temporal heterogeneities in that more mouse lemurs were observed in degraded habitat during the dry season (Table 2A), whereas there was no difference between early and late rainy season counts in any species (Table 2B). In most cases, the number of interand intraspecific pairs of individuals within $150 \mathrm{~m}$ was higher in degraded habitat during the dry season, whereas more pairs were observed within recognition distance in non-degraded habitat during the rainy season (Table 3). 
TABLE 3 | Number of transect walks per scenario as well as the numbers of inter- and intraspecific pairs of individuals detected within 150 m on single transect walks.

\begin{tabular}{|c|c|c|c|c|c|}
\hline & \multicolumn{2}{|c|}{ Dry season } & \multicolumn{2}{|c|}{ Wet season } & \multirow[b]{2}{*}{ Sum of pairs } \\
\hline & Non-degraded & Degraded & Non-degraded & Degraded & \\
\hline Number of transect walks & 37 & 34 & 33 & 23 & \\
\hline \multicolumn{6}{|l|}{ Interspecific pairs } \\
\hline M. berthae - M. murinus & 9 & 22 & 12 & 0 & 43 \\
\hline M. berthae - M. coquereli & 8 & 6 & 3 & 2 & 19 \\
\hline M. berthae - C. medius & - & - & 42 & 4 & 46 \\
\hline M. murinus - M. coquereli & 0 & 7 & 3 & 6 & 16 \\
\hline M. murinus - C. medius & - & - & 69 & 34 & 103 \\
\hline M. coquereli - C. medius & - & - & 15 & 7 & 22 \\
\hline \multicolumn{6}{|l|}{ Intraspecific pairs } \\
\hline M. berthae & 15 & 12 & 7 & 1 & 35 \\
\hline M. murinus & 95 & 254 & 160 & 43 & 552 \\
\hline M. coquereli & 3 & 4 & 1 & 7 & 15 \\
\hline C. medius & - & - & 99 & 24 & 123 \\
\hline
\end{tabular}

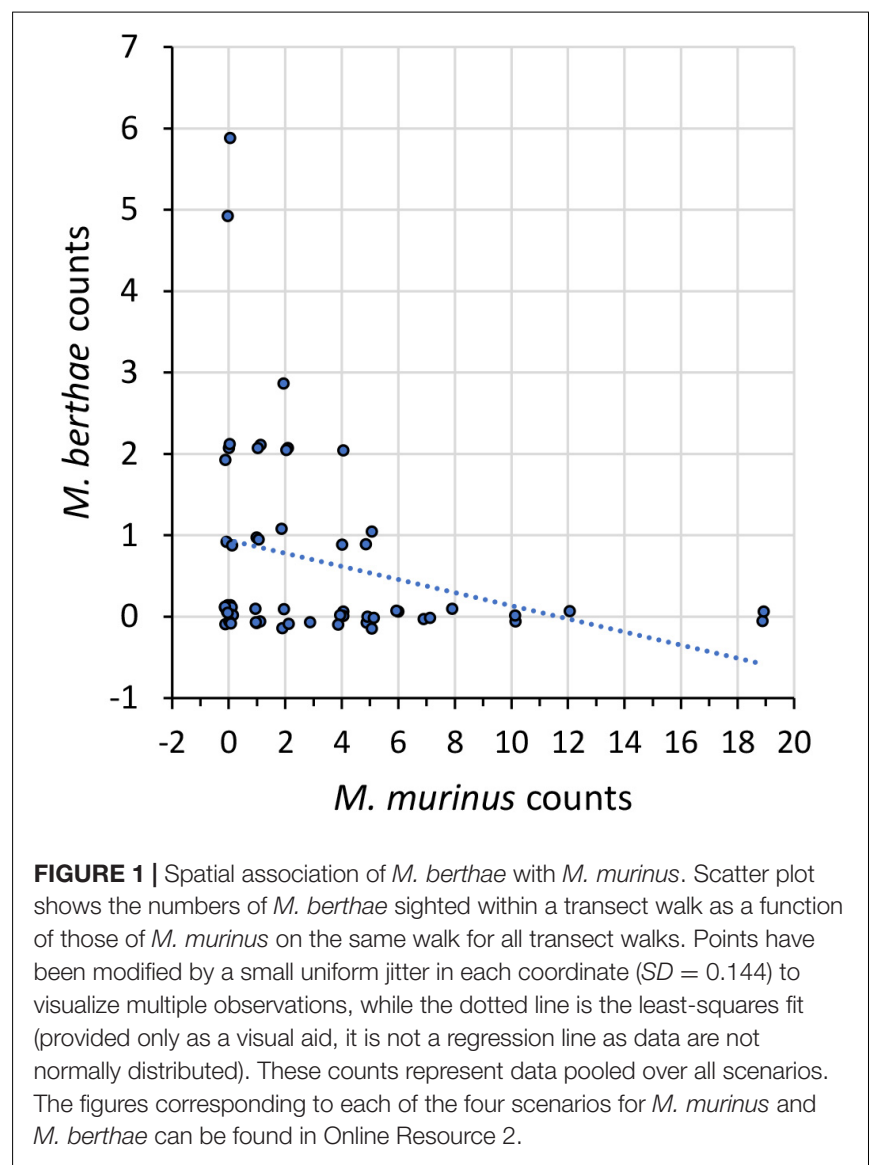

To test the first set of hypotheses (H1), we investigated whether there is evidence of avoidance between $M$. murinus and $M$. berthae. Results in Table $\mathbf{4 A}$ and Figure $\mathbf{1}$ (see also Supplementary Figure 1 in Online Resource 2) clearly showed a tendency for mutual exclusion, supporting Hypothesis 1a, as nine of the ten indices ( $\rho$ and $T$ ) are negative, although only three of these values were statistically significant. The pooled data showed significant evidence of segregation at both scales. At the local scale, there was segregation during the dry season in non-degraded habitat supporting Hypothesis $1 \mathrm{~b}$, but no evidence of segregation in the degraded habitats and thus no support for Hypothesis 1c.

Hypothesis 2a predicted segregation between $M$. murinus and $M$. coquereli, which was observed at the regional scale in the pooled data (Figure 2A) and in all scenarios but in degraded habitat during the dry season (Table 4B and Supplementary Figure 2A). In contrast, no segregation was observed between $M$. berthae and $M$. coquereli (Table 4B and Figure 2B), complying with Hypothesis $2 \mathrm{~b}$. On the regional scale, those two species were even positively associated in degraded habitat during the dry season (Supplementary Figure 2B). Negative spatial association of $M$. murinus and $M$. coquereli within transects was limited to the dry season with food scarcity (Supplementary Figure 2A) and thus conforms with Hypothesis 2c.

Segregation patterns found between $M$. murinus and C. medius complied with Hypothesis 3a (Table 4C and Figure 3A). Lack of avoidance between M. berthae and C. medius on the regional scale (Table $4 \mathrm{C}$ and Figure $3 \mathrm{~B}$ ) and attraction within transects in non-degraded habitats (Supplementary Figure 3B) supported Hypothesis 3b. Segregation of M. murinus and $C$. medius was detected at the regional level in non-degraded habitat (Supplementary Figure 3A) and within transects in degraded habitat, which indicates both competition for tree holes and food according to Hypothesis $3 c$.

\section{DISCUSSION}

\section{Competition Between Microcebus spp.}

Mouse lemur coexistence appears to be stabilized by avoidance of heterospecific individuals and movements in a spatio-temporally varying environment. Spatial segregation between the mouse lemurs was indicated by the pooled data at the regional and 

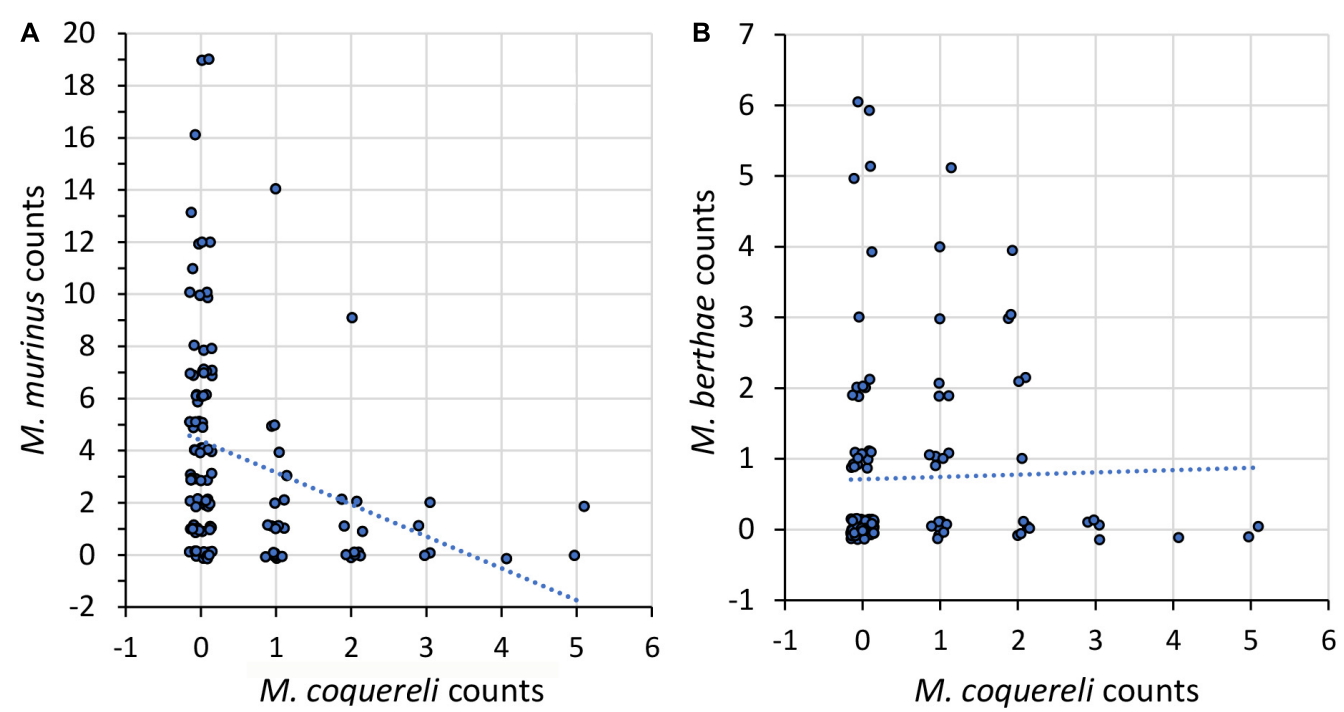

FIGURE 2 | As in Figure 1 but for numbers of sighted (A) M. murinus and (B) M. berthae as a function of the number of $M$. coquereli individuals.
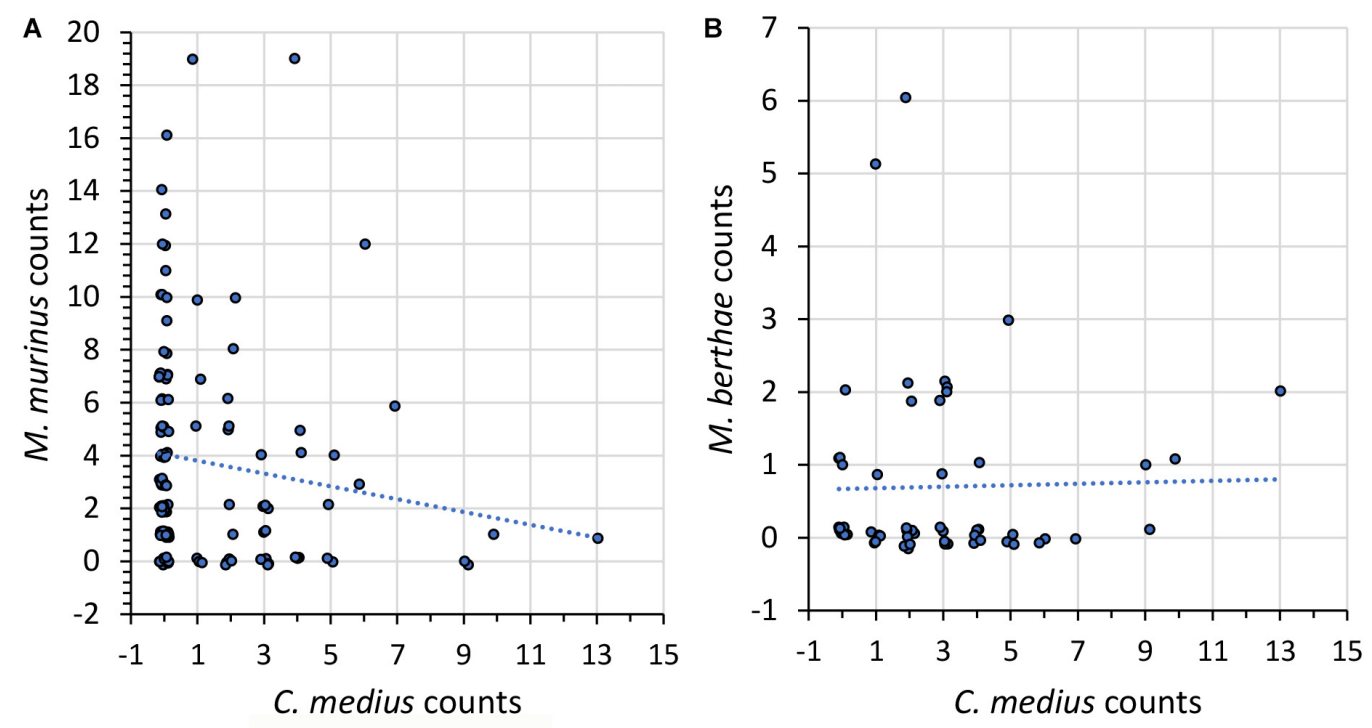

FIGURE 3 | As in Figure 1 but for numbers of sighted (A) M. murinus and (B) M. berthae as a function of the number of $C$. medius individuals.

local scale. During the dry season, the distribution pattern of individuals within transects also indicated interspecific avoidance, with significant results in non-degraded habitat and a non-significant trend in degraded habitat. These results generally support the notion of spatial exclusion, which is in line with the conclusion of previous studies that mouse lemur differentiation in feeding niches and microhabitat utilization was insufficient to prevent competitive exclusion when resources are scarce (Ganzhorn and Kappeler, 1996; Schwab and Ganzhorn, 2004; Dammhahn and Kappeler, 2008b, 2009, 2010). Coexistence in a spatially heterogeneous competitive environment was also considered a probable explanation for the co-occurrence of closely related mouse lemur species in north-western Madagascar (Rakotondravony and Radespiel, 2009).
However, mouse lemur association did not meet the prediction that spatial segregation should be particularly pronounced in degraded habitat. Small-sized nocturnal lemurs have evolved specific adaptations to cope with the extremely seasonal dry forest habitats of western Madagascar. Female M. murinus enter torpor to save energy (Schmid and Kappeler, 2005), which reduces the number of animals competing for over limited food resources (Thorén et al., 2011b). Moreover, species escape intense interspecific competition over food by shifting their diets to fallback food: sugary secretions of homopteran larvae represent a key fallback food for M. murinus during the dry season, while $M$. berthae relies on this feeding resource year-round (Dammhahn and Kappeler, 2008a). Similar to M. berthae and M. murinus, feeding niche overlap 
TABLE 4 | (A-C) Interspecific correlation coefficient for individual numbers on transects and index $T$ (Eq. 1) measuring interspecific aggregation within transects for five species combinations and four different scenarios.

(A) Interspecific associations between the two mouse lemur species.

\begin{tabular}{|c|c|c|c|c|}
\hline \multirow[t]{3}{*}{ Scenario } & \multicolumn{4}{|c|}{ M. berthae - M. murinus } \\
\hline & \multicolumn{2}{|c|}{ regional } & \multicolumn{2}{|c|}{ within transects } \\
\hline & $\rho$ & $P$ & $T$ & $P$ \\
\hline Non-degraded habitat / dry season & -0.30 & 0.0708 & -0.13 & $0.013^{*}$ \\
\hline Degraded habitat / dry season & -0.24 & 0.1657 & -0.06 & 0.053 \\
\hline Non-degraded habitat / wet season & -0.29 & 0.0961 & +0.06 & 0.849 \\
\hline Degraded habitat / wet season & -0.15 & 0.4971 & -0.15 & 0.21 \\
\hline Pooled & -0.30 & $0.0005^{\star \star}$ & -0.05 & $0.045^{*}$ \\
\hline
\end{tabular}

(B) Interspecific associations of mouse lemurs and $M$. coquereli.

M. berthae - M. coquereli

\begin{tabular}{|c|c|c|c|c|c|c|c|c|}
\hline & & & & & \\
\hline & \multicolumn{2}{|c|}{ regional } & \multicolumn{2}{|c|}{ within transects } & \multicolumn{2}{|c|}{ regional } & \multicolumn{2}{|c|}{ within transects } \\
\hline & $\rho$ & $\boldsymbol{P}$ & $T$ & $P$ & $\rho$ & $P$ & $T$ & $\boldsymbol{P}$ \\
\hline Non-degraded habitat / dry season & +0.16 & 0.3509 & -0.07 & 0.292 & -0.57 & $0.0002^{\star \star}$ & -0.11 & $0.040^{*}$ \\
\hline Degraded habitat /dry season & +0.35 & $0.0423^{*}$ & -0.13 & 0.197 & -0.22 & 0.2127 & -0.08 & $0.001^{\star \star}$ \\
\hline Non-degraded habitat / wet season & +0.09 & 0.6071 & -0.02 & 0.548 & -0.39 & $0.0232^{*}$ & +0.02 & 0.788 \\
\hline Degraded habitat /wet season & +0.25 & 0.2547 & -0.14 & 0.383 & -0.58 & $0.0039^{\star \star}$ & -0.08 & 0.218 \\
\hline Pooled & +0.16 & 0.0731 & -0.03 & 0.354 & -0.43 & $0.0000^{\star \star}$ & -0.05 & $0.013^{\star}$ \\
\hline
\end{tabular}

(C) Interspecific associations of mouse lemurs and C. medius.

Scenario

Non-degraded habitat / dry season

Degraded habitat /dry season

Non-degraded habitat / wet season

Degraded habitat / wet season

Pooled

\begin{tabular}{|c|c|c|c|c|c|c|c|c|}
\hline & & \\
\hline & \multicolumn{2}{|c|}{ regional } & \multicolumn{2}{|c|}{ within transects } & \multicolumn{2}{|c|}{ regional } & \multicolumn{2}{|c|}{ within transects } \\
\hline & $\rho$ & $P$ & $T$ & $P$ & $\rho$ & $P$ & $T$ & $P$ \\
\hline Non-degraded habitat / wet season & -0.11 & 0.5495 & +0.14 & $0.044^{*}$ & -0.34 & $0.0500^{\star}$ & -0.07 & 0.053 \\
\hline Degraded habitat / wet season & +0.01 & 0.9776 & -0.12 & 0.36 & +0.10 & 0.6500 & -0.21 & $0.011^{\star}$ \\
\hline Pooled & +0.03 & 0.7771 & +0.05 & 0.774 & -0.21 & $0.0186^{\star}$ & -0.06 & $0.003^{\star \star}$ \\
\hline
\end{tabular}

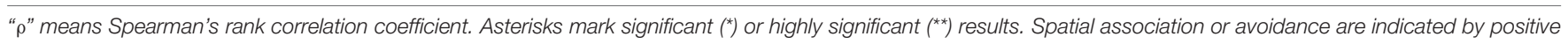
or negative T-values.

between sympatric Microcebus ravelobensis and M. murinus in northwestern Madagascar was found to be reduced by slight differences in dietary composition: $M$. ravelobensis relies heavily on insect secretions whereas a higher feeding plasticity in M. murinus was indicated by more pronounced seasonal shifts (Thorén et al., 2011b).

Mouse lemur individuals were more frequently encountered in degraded habitat during the dry season compared to the wet season (Table 2A), possibly tracking homopteran larvae that occur in higher abundance along forest edges (Corbin and Schmid, 1995). In north-western Madagascar, capture rates of $M$. ravelobensis were also higher in edge habitats, where small insects were more abundant (Burke and Lehman, 2014). Higher availability of insect prey was also assumed to explain the positive edge response of $M$. rufus in the eastern Malagasy rain forest (Lehman et al., 2006a,c). The seasonal differences correspond to results of an earlier study showing that $M$. murinus extended their foraging efforts to a greater number of transects during the dry season whereas they concentrated on fewer transects during the wet season (Schäffler et al., 2015). The population of
$M$. berthae was largely confined to non-degraded habitat during the wet season but occupied also degraded habitats during the dry season. Habitat partitioning along anthropogenic disturbance gradients was indicated during the dry season in degraded habitat as $M$. berthae avoided anthropogenic environments, whereas M. murinus was found in close vicinity to villages (Schäffler et al., 2015). A greater flexibility in habitat selection may thus enable $M$. murinus to exclusively access resources, corresponding to a high ecological generalization that can also be concluded from $M$. murinus prevalence in a wide range of environments (Kamilar et al., 2016). However, there is evidence for divergent habitat selectivity in different parts of Madagascar. In northwestern Madagascar, M. murinus was associated with older and less disturbed forests whereas sympatric M. ravelobensis showed more flexibility in habitat use with edge tolerance (Rendigs et al., 2003; Lehman, 2016) and occupied a greater proportion of habitat patches than M. murinus in a fragmented landscape (Steffens and Lehman, 2016). In the spiny forest of southeastern Madagascar, M. murinus was found to prefer larger trees than M. griseorufus only where the mouse lemurs occurred in 
sympatry, whereas habitat selectivity of either species was low in allopatric populations (Rakotondranary and Ganzhorn, 2012).

\section{Mouse Lemur Interactions With M. coquereli}

Both mouse lemurs should be affected by resource competition with $M$. coquereli during the dry season when all three species feed on homopteran secretions (Kappeler, 2003). We observed negative association of $M$. coquereli and M. murinus in most scenarios and across scales. The regional scale association of $M$. berthae and $M$. coquereli indicate that feeding competition is relaxed in degraded habitat during the dry season, probably due to high insect abundance in edge habitat (Burke and Lehman, 2014). Moreover, the feeding niches of M. murinus and $M$. coquereli are differentiated in fruit and animal matter (Dammhahn and Kappeler, 2014). As competition for food alone cannot explain the observed interspecific segregation, opportunistic predation by $M$. coquereli may be an additional cause for spatial avoidance (Schliehe-Diecks et al., 2010).

Interspecific mouse lemur distribution may thus be interpreted as the outcome of competition between individuals that simultaneously differ in their ability to exploit resources and their susceptibility to predation (Grand and Dill, 1999), i.e., as a consequence of "apparent competition" (e.g., Holt and Lawton, 1994). The contribution of predators to competitive coexistence of prey species varies with heterogeneity of predation risk in space and time, rather than with magnitude of the pressure (Kotler et al., 1994). As the superior competitor for enemy-free space, $M$. murinus can escape (intraguild) predation pressure during the dry season by seeking refuge in the vicinity of villages (Schäffler et al., 2015). In contrast, disturbance-intolerant $M$. berthae cannot avoid interspecific interactions with $M$. coquereli in intact habitat, but profits from reduced competition with the congener in refuges created by the giant mouse lemur.

It remains puzzling why only $M$. murinus appears to be affected by $M$. coquereli. One explanation would be a specific preference of $M$. coquereli for one mouse lemur over the other, but $M$. murinus may rather be more exposed to opportunistic predation than $M$. berthae due to its more clustered social organization (M. murinus: Eberle and Kappeler, 2002, 2004, 2006; Wimmer et al., 2002; M. berthae: Dammhahn and Kappeler, 2005, 2009; see also Table 3). Moreover, M. murinus occurs in higher population densities (180 individuals $\mathrm{km}^{-2}$ ) than M. berthae ( 80 individuals $\mathrm{km}^{-2}$ : Schäffler, 2012), so it may be the more profitable prey for $M$. coquereli because there are simply more individuals available. Finally, the two mouse lemur species may respond differently to (intraguild) predators. Variation in sleeping site utilization between mouse lemur species was interpreted as an outcome of divergent anti-predator strategies. In M. murinus, females hiding in tree holes likely profit from reduced risk of detection by predators and from protected shelters, so females can even afford to sleep in kin groups (Radespiel et al., 1998, 2003). Male M. murinus, in contrast, most often rest alone in open vegetation, which may be the best predator-avoidance strategy when high-quality tree holes are monopolized by females (Radespiel et al., 1998). In $M$. berthae, both sexes sleep in less protected sites such as leaf nests and rather rely on cryptic behavior by resting solitarily or occasionally in small sleeping associations (Dammhahn and Kappeler, 2005). The rapid escape response reported for $M$. ravelobensis that also sleeps in open vegetation (Radespiel et al., 2003) was not observed in M. berthae, which may instead pursue a more cryptic strategy to avoid detection by a predator. The biogeographic history of mouse lemurs may also explain their divergent avoidance behavior with respect to $M$. coquereli. With its presumed origin in the area of microendemism comprising Menabe Central (Wilmé et al., 2006; Weisrock et al., 2010) and its limited range entirely overlapping with that of $M$. coquereli, $M$. berthae may have evolved specific strategies to cope with the intraguild predator. In contrast, $M$. murinus also occurs in areas where $M$. coquereli is absent and the genetic population structure in north-western Madagascar indicated a rather recent range expansion (Schneider et al., 2010) from its presumed origin in south-western Madagascar (Yoder et al., 2000; Olivieri et al., 2007). Owing to less distributional overlap and a shorter history of coexistence, $M$. murinus may thus be less well adapted than $M$. berthae to intraguild-predation by $M$. coquereli.

\section{Mouse Lemur Interactions With C. medius}

The interspecific distribution of mouse lemur individuals during the wet season supports the hypothesis that $C$. medius also plays a central role in stabilizing competitive mouse lemur coexistence. Spatial segregation of $M$. murinus and C. medius contrasted with the positive association between $M$. berthae and C. medius in nondegraded habitat.

Interspecific segregation between $M$. murinus and C. medius in relation to habitat heterogeneity indicated both regional-scale competition for suitable tree holes that are predominately found in old growth forest (Schwab and Ganzhorn, 2004) and for food within transects. Similar to Cheirogaleus major that is more abundant in the rainforest interior with large trees than in edge habitat (Lehman et al., 2006a,c), C. medius occurs in highest population densities in non-degraded habitat and far from villages (Schäffler and Kappeler, 2014b). By colonizing anthropogenic environments, $M$. murinus may avoid agonistic interactions with the superior competitor for tree holes (Schwab and Ganzhorn, 2004; Schäffler, 2012; Schäffler et al., 2015). In contrast, interspecific avoidance between $M$. murinus and C. medius individuals within transects was most pronounced in degraded habitat, indicating feeding competition, the context in which $C$. medius was observed to outcompete $M$. murinus (Ganzhorn and Kappeler, 1996).

Spatial consequences of resource competition have also been reported in other lemur communities. Sympatric lemur species do not only compete within but also between functional groups (Ganzhorn, 1997), and even competition between taxa of different orders may determine the composition of species assemblages: the absence of $M$. coquereli and ecologically equivalent species in eastern Madagascar was suggested to result 
not only from competition for fruit with C. major, but also from competitive exclusion by the carnivorous ring-tailed mongoose (Galidia elegans; Ganzhorn et al., 1999).

Positive spatial association of $M$. berthae and $C$. medius individuals agreed with our prediction that crowding in most productive habitats, where fruit and animal matter is highly abundant during the wet season, outweighs effects of interspecific competition caused by pronounced feeding niche overlap. Just as $C$. medius, C. major in the rain forest near Andasibe is only active during the hot season when young leaves, flowers and fruit are abundant and entirely overlaps in food and habitat utilization with the else well separated niches of co-occurring species (Ganzhorn, 1989). In addition, differential use of both, structural microhabitat features (Schwab and Ganzhorn, 2004) and sleeping sites (Fietz, 2003; Dammhahn and Kappeler, 2005), likely helps to avoid direct interference between $M$. berthae and $C$. medius and allows for positive spatial association of individuals in non-degraded habitat. Similar to M. berthae, M. ravelobensis uses open sleeping sites like lianas or leaf nests and does not compete for three holes that represent a critical resource for other cheirogaleids (Rendigs et al., 2003).

\section{Mechanisms Stabilizing Competitive Coexistence}

Spatial segregation patterns like those documented between $M$. berthae and M. murinus as well as between $M$. murinus and $C$. medius were frequently observed in other primates. Lemur assemblages in the Malagasy rain forests have even more sympatric species and co-occurring congeners than communities in the western dry deciduous forest (Ganzhorn et al., 1999). In the fragmented rain forest of Kianjavato, several cooccurring gregarious lemurs that are diurnal and frugivorous were found to reduce interspecific competition by segregating their core areas (Holmes et al., 2019). Similarly, spatial segregation of co-occurring primates in Indonesia (Tilson and Tenaza, 1982), Borneo (Rodman, 1973), and Guyana (Levi et al., 2013) were considered a consequence of interspecific competition. Agonistic behavior between sympatric species can cause spatial segregation and is often pronounced between species in taxonomic assemblages (Dempster and Perrin, 1990). While C. medius was reported to prevail over other cheirogaleids in contest competition (Ganzhorn and Kappeler, 1996; Ganzhorn et al., 1999), aggressive interactions between mouse lemurs at food resources are rather rare (Dammhahn and Kappeler, 2005; Thorén et al., 2016). However, spatial exclusion in coexisting species may also occur without conflicts if subordinate species use auditory or olfactory cues to detect and avoid dominant species that gain exclusive access to resource-rich microhabitats (Dickman, 1991; Rychlik and Zwolak, 2005).

Moreover, variations in habitat utilization and interspecific association patterns in a spatio-temporally heterogeneous environment likely facilitate mouse lemur coexistence. Many sympatric species change their feeding or ranging behavior in response to increased competition during periods of resource scarcity. On the Masoala Peninsula of eastern Madagascar, cooccurring lemurs adapt their foraging behavior to variations in food availability, feeding jointly during the productive hot season but in spatial separation during the cold season (Vasey, 2000). Sympatric new world primates in Bolivia maintain longterm associations throughout the year by using different food resources when fruits are scarce (Porter, 2001). Also, habitat partitioning between competing haplorrhines in Kenya was observed to change with resource supply with one species shifting its foraging grounds during dry periods (Wahungu, 1998). Divergent habitat selection also stabilized coexistence in other small mammals (Aunapuu and Oksanen, 2003). Thus, there is evidence from various taxonomic assemblages that behavioral flexibility stabilizes competitive coexistence of ecologically similar species.

Finally, there are numerous examples of predators indirectly increasing species diversity in ecological communities (Wootton, 1994; Estes et al., 2011). Spatial segregation of resource competitors in relation to predation risk have been observed in many taxa (e.g., Paine, 1966; Hanski and Henttonen, 1996; Kullberg and Ekman, 2000; Rochette and Grand, 2004). Specific preference of intraguild predators for certain prey species are known from chimpanzees (Stanford, 1995; Teelen, 2007a,b, 2008), but the apparent preference of M. coquereli for M. murinus may rather be related to differences in the social organization between the mouse lemurs. In Finland, a more gregarious and abundant vole species prevailed over its sympatric congener in competition for space (Hughes et al., 2010) but was also more easily detectable and rewarding prey for predators (Norrdahl and Korpimäki, 1993; Koivisto et al., 2007).

\section{CONCLUSION AND CONSERVATION IMPLICATIONS}

This study extends the insights of previous single-site investigations of this cheirogaleid assemblage (Schwab and Ganzhorn, 2004; Dammhahn and Kappeler, 2008a,b) to a wider range of spatial scales, including the local scale, and links them to observed regional-scale patterns (Schäffler et al., 2015). To measure inter-specific interactions within transects, we developed an "Inter-Specific Index of Attraction" (ISIA) which we tested for statistical significance against a null model based on a combination of randomization and bootstrapping, which controls for intra-specific clustering.

The distribution of mouse lemurs indicated habitat partitioning at different levels. First, we detected a higher number of individuals in intact habitats during the wet season and in degraded habitat during the dry season. Our local scale analyses thus reconfirmed that both mouse lemur species crowded in most suitable forest areas during the wet season and tracked scarce resources in degraded habitats during the dry season, corresponding to the pattern described on the population-level (Schäffler et al., 2015). Interspecific competition between individuals within transects was indicated during the dry season predominately in non-degraded habitat, whereas spatial 
segregation between $M$. berthae by $M$. murinus populations was limited to degraded habitat during the dry season (Schäffler et al., 2015). Increased use of degraded habitats when resources are scarce may therefore result from competitive exclusion between individuals in intact forests. Analyses incorporating dwarf and giant mouse lemurs with novel methods expanded knowledge on the interactions with third agents (Schäffler et al., 2015). The interspecific distribution of individuals confirmed that $C$. medius and $M$. coquereli mitigate competitive pressure on $M$. berthae and consequently stabilize mouse lemur coexistence. Our individual-level analyses revealed that the displacement of $M$. murinus by intraguild predator $M$. coquereli and the positive association between $M$. berthae and $M$. coquereli are not limited to non-degraded habitat during the dry season as previously suggested by the population-level distribution (Schäffler et al., 2015). Moreover, avoidance of superior competitor C. medius by $M$. murinus individuals and simultaneous local scale cooccurrence of $M$. berthae and $C$. medius during the wet season was not evidenced to date (Schwab and Ganzhorn, 2004; Schäffler et al., 2015). Given the variation in cheirogaleid distribution across spatio-temporal heterogeneities, the spatial competition hypothesis (Tilman, 1994) appears best suited to reconcile individual-level interspecific exclusion and population-level coexistence of the two mouse lemur species.

The complex ecological structure in the cheirogaleid assemblage of Menabe Central essentially depends on habitat quality and heterogeneity that provide cheirogaleids with refuges from unfavorable interspecific interactions and stabilizes competitive mouse lemur coexistence. Microcebus berthae was categorized as "Critically Endangered" in the recently updated IUCN Red List of Threatened Species (Markolf et al., 2020). Extensive habitat loss and degradation due to slash and burn agriculture results in continuing decline in the area of occupancy and extent of occurrence. A population decrease by more than $80 \%$ over 10 years is not only expected as a direct consequence of ongoing habitat loss, but also as interspecific interactions with dwarf and giant mouse lemurs that stabilize competitive coexistence of mouse lemurs depend on intact habitat. Contrasting association patterns of mouse lemurs between continuous forest sites (Rakotondravony and Radespiel, 2009) and isolated patches (Steffens and Lehman, 2016) in north-western Madagascar demonstrate the impact of habitat fragmentation on interaction regimes.

Species that are subject to the same disturbances do not always react in a similar manner, even if phylogenetically closely related (Lehman et al., 2006a,b,c; Irwin et al., 2010; Herrera et al., 2011; Lehman, 2016). It appears surprising that the massive landscapelevel disturbances of recent times have not resulted in more lemur extinctions (Lehman et al., 2006c). However, species extinction in patchy environments may be time-delayed, and particularly threaten species that are abundant in intact habitat due to an interspecific trade-off between colonization and competitive abilities (Tilman et al., 1994). The loss of any species in ecological communities will have indirect effects on multiple levels (Strauss, 1991) and may trigger an extinction cascade with dramatic consequences for system stability (Allesina and Levine, 2011).

Genetic studies revealed that $M$. coquereli compensates for extensive population fluctuations (Kappeler, 2003) by immigration from adjacent populations (Markolf et al., 2008). Continuing habitat fragmentation may permanently extirpate the species from forest patches if isolation prevents recolonization (Irwin et al., 2009). Metapopulation models for the eight species comprising a lemur assemblage in north-western Madagascar revealed differences in the ability to cope with habitat fragmentation: while the occurrence of all lemurs depended on patch size, C. medius was particularly susceptible to reduction of area and isolation of poorly connected habitat fragments (Steffens and Lehman, 2018). Further loss, degradation and fragmentation of dry forests in Menabe Central will likely cause a reduction of population size in $M$. coquereli and $C$. medius and release $M$. murinus from intraguild predation and resource competition. Increasing interspecific competition between the mouse lemurs would then further reduce the suitability of remaining habitat for $M$. berthae. In these scenarios, one mouse lemur species might drive the other one to extinction (Schwab and Ganzhorn, 2004). Protection of remaining intact forest parts as well as restoration of degraded habitat and connectivity in the central Menabe region of western Madagascar is therefore critical to preserve $M$. berthae and coexisting species in this global biodiversity hotspot.

\section{NOTES ON THE STATISTICAL APPROACH}

In this paper we tested interspecies associations involving mouse lemurs. Primarily, we were looking for negative associations that might be caused by competitive or (intraguild) predatory interactions. To do this we developed the "Inter-Species Index of Attraction" (ISIA) for local interactions on transects. We used a null model distinct from the ideal gas model because intraspecific clustering is in effect for all species and can obscure the effect of interspecies associations. To control for this, we used a null model based on a combination of randomization and bootstrapping to determine the significance of observed interactions. Our simulation approach comparing the neutral with the observed individual-level distribution of co-occurring species allowed for investigating interspecific interactions on a local scale and link it to observed regional scale patterns rather than examining only spatial overlap of populations (Schäffler et al., 2015). Moreover, our data collected from the cheirogaleid assemblage's entire area of occupancy considered spatial heterogeneities and thus generated knowledge beyond the insights of previous studies at single sites (e.g. Schwab and Ganzhorn, 2004; Dammhahn and Kappeler, 2008a,b).

The statistical tests used by us in both regional and local analyses are non-parametric. One of the reasons for this is to avoid errors that might arise due to non-normality and zeroinflation in statistical tests. Another advantage of non-parametric statistics is that they are more robust against the effects of spatial autocorrelation. Some degree of spatial autocorrelation arising from external factors (Lennon, 2000) is likely to be present. One of the important external factors is habitat quality, which we controlled for by the fundamental structure of our data: dividing scenarios between degraded versus non-degraded. In comparisons between transect walks, the relatively large distances 
between transects $(>1 \mathrm{~km})$ also reduces the effect of spatial autocorrelation. Another spatial issue arises from the fact that transect distribution was not strictly random, owing to the logistical difficulties of sampling a large number of transects in areas of dense forest.

\section{DATA AVAILABILITY STATEMENT}

The raw data supporting the conclusions of this article will be made available by the corresponding author upon request.

\section{ETHICS STATEMENT}

The animal study was reviewed and approved by Bundesamt für Naturschutz (BfN) in Germany; Ministère de l'Environment et des Eaux et Forêts (MINEEF), CAFF/CORE committee and the National Association for the Management of Protected Areas (ANGAP) in Madagascar.

\section{AUTHOR CONTRIBUTIONS}

LS originally formulated the idea, developed the methodology, conducted fieldwork, and wrote the manuscript. PK provided the research facility and supported project implementation. LS and $\mathrm{JH}$ processed the data and performed analyses. $\mathrm{JH}$ developed the models and ran statistical analyses. All authors contributed to the article, approved the submitted version and agreed to be accountable for all aspects of the work.

\section{REFERENCES}

Abrams, P. (1983). The theory of limiting similarity. Annu. Rev. Ecol. Syst. 14, 359-376. doi: 10.1146/annurev.es.14.110183.002043

Allesina, S., and Levine, J. M. (2011). A competitive network theory of species diversity. Proc. Natl. Acad. Sci. U.S.A. 108, 5638-5642. doi: 10.1073/pnas. 1014428108

Amarasekare, P. (2003). Competitive coexistence in spatially structured environments: a synthesis. Ecol. Lett. 6, 1109-1122. doi: 10.1046/j.14610248.2003.00530.x

Andriatsitohaina, B., Romero-Mujalli, D., Ramsay, M. S., Kiene, F., Rasoloharijaona, S., Rakotondravony, R., et al. (2020). Effects of habitat edges on vegetation structure and the vulnerable golden-brown mouse lemur (Microcebus ravelobensis) in northwestern Madagascar. BMC Ecol. 20:69.

Ashehoug, E. T., and Callaway, R. M. (2015). Diversity increases indirect interactions, attenuates the intensity of competition, and promotes coexistence. Am. Nat. 186, 452-459. doi: 10.1086/682901

Aunapuu, M., and Oksanen, T. (2003). Habitat selection of coexisting competitors: a study of small mustelids in northern Norway. Evol. Ecol. 17, 371-392. doi: 10.1023/a:1027356618140

Beaudrot, L. H., and Marshall, A. J. (2011). Primate communities are structured more by dispersal limitation than by niches. J. Anim. Ecol. 80, 332-341. doi: 10.1111/j.1365-2656.2010.01777.x

Bidner, L. R. (2014). Primates on the menu: direct and indirect effects of predation on primate communities. Int. J. Primatol. 35, 1164-1177. doi: 10.1007/s10764014-9797-x

Bonsall, M. B., and Hassell, M. P. (1997). Apparent competition structures ecological assemblages. Nature 388, 371-373. doi: 10.1038/41084

Bonsall, M. B., and Holt, R. D. (2003). The effects of enrichment on the dynamics of apparent competitive interactions in stage-structured systems. Am. Nat. 162, 780-795. doi: $10.1086 / 379203$

\section{FUNDING}

This study was completed with financial support from the German Primate Center (DPZ), Primate Conservation Incorporated (PCI Grant \#359), Conservation International (CI), Durrell Wildlife Conservation Trust (DWCT) and with authorization by the CAFF/CORE committee, and the National Association for the Management of Protected Areas (ANGAP). Open access publication is kindly supported by the Zoological Research Museum Alexander Koenig (ZFMK).

\section{ACKNOWLEDGMENTS}

We thank Nielsen Rabarijaona, Rémy Ampataka, Raza Rakotonirina, Jean-Pierre Tolonjanahary, and Tiana Andrianjanahary for their expert assistance and outstanding commitment to the surveys, and Léonard Razafimanantsoa and Rodin Rasoloarison for logistic support during fieldwork. We also appreciate the suggestions of editor $\mathrm{MB}$ and the two reviewers $\mathrm{DH}$ and TS who helped to significantly improve our manuscript.

\section{SUPPLEMENTARY MATERIAL}

The Supplementary Material for this article can be found online at: https://www.frontiersin.org/articles/10.3389/fevo.2021. 585781/full\#supplementary-material

Bourlière, F. (1985). Primate communities: their structure and role in tropical ecosystems. Int. J. Primatol. 6, 1-26. doi: 10.1007/bf02693694

Braune, P., Schmidt, S., and Zimmermann, E. (2005). Spacing and group coordination in a nocturnal primate, the golden brown mouse lemur (Microcebus ravelobensis): the role of olfactory and acoustic signals. Behav. Ecol. Sociobiol. 58, 587-596. doi: 10.1007/s00265-005-0944-4

Bruno, J. F., Stachowicz, J. J., and Bertness, M. D. (2003). Inclusion of facilitation into ecological theory. Trends. Ecol. Evol. 18, 119-125. doi: 10.1016/s01695347(02)00045-9

Buckland, S. T., Anderson, D. R., Burnham, K. P., Laake, J. L., Borchers, D. L., and Thomas, L. (2001). Introduction to Distance Sampling: Estimating Abundance of Biological Populations. New York, NY: Oxford University Press.

Buckland, S. T., Plumptre, J. A., Thomas, L., and Rexstad, E. A. (2010). Design and analysis of line transect surveys for primates. Int. J. Primatol. 31, 833-847. doi: 10.1007/s10764-010-9431-5

Burke, R. J., and Lehman, S. M. (2014). Edge effects on morphometrics and body mass in two sympatric species of mouse lemurs in madagascar. Folia Primatol. 85, 277-291. doi: 10.1159/000360082

Buzzard, P. J. (2010). Polyspecific associations of Cercopithecus campbelli and C. petaurista with C. diana: what are the costs and benefits? Primates 51, 307-314. doi: 10.1007/s10329-010-0203-9

Caswell, H. (1978). Predator-mediated coexistence: a nonequilibrium model. Am. Nat. 112, 127-154. doi: 10.1086/ 283257

Chesson, P. (2000b). Mechanisms and maintenance of species diversity. Annu. Rev. Ecol. Syst. 31, 343-366. doi: 10.1146/annurev.ecolsys.31.1.343

Chesson, P. (2000a). General theory of competitive coexistence in spatially varying environments. Theor. Popul. Biol. 58, 211-237. doi: 10.1006/tpbi.2000.1486

Corbin, G., and Schmid, J. (1995). Insect secretions determine habitat use patterns by a female lesser mouse lemur (Microcebus murinus). Am. J. Primatol. 37, 317-324. doi: 10.1002/ajp.1350370406 
Dammhahn, M., and Kappeler, P. M. (2005). Social system of Microcebus berthae, the world's smallest primate. Int. J. Primatol. 26, 407-435. doi: 10.1007/s10764005-2931-z

Dammhahn, M., and Kappeler, P. M. (2008a). Comparative feeding ecology of sympatric Microcebus berthae and M. murinus. Int. J. Primatol. 29, 567-1589.

Dammhahn, M., and Kappeler, P. M. (2008b). Small-scale coexistence of two mouse lemur species (Microcebus berthae and M. murinus) within a homogeneous competitive environment. Oecologia 157, 473-483. doi: 10.1007/ s00442-008-1079-x

Dammhahn, M., and Kappeler, P. M. (2009). Females go where the food is: does the socio-ecological model explain variation in social organisation of solitary foragers? Behav. Ecol. Sociobiol. 63, 393-352.

Dammhahn, M., and Kappeler, P. M. (2010). Scramble or contest competition over food in solitarily foraging mouse lemurs (Microcebus spp.): new insights from stable isotopes. Am. J. Phys. Anthropol. 141, 181-189.

Dammhahn, M., and Kappeler, P. M. (2014). Stable isotope analyses reveal dense trophic species packing and clear niche differentiation in a Malagasy primate community. Am. J. Phys. Anthropol. 153, 249-259. doi: 10.1002/ajpa.22426

Dausmann, K. H., Glos, J., Ganzhorn, J. U., and Heldmaier, G. (2004). Hibernation in a tropical primate. Nature 429, 825-826. doi: 10.1038/429825a

Dempster, E. R., and Perrin, M. R. (1990). Interspecific aggression in sympatric Gerbillurus species. Z. Säugetierkd. 55, 392-398.

Denis, T., Richard-Hansen, C., Brunaux, O., Guitet, S., and Hérault, B. (2019). Birds of a feather flock together: functionally similar vertebrates positively co-occur in Guianan forests. Ecosphere 10, 1-17.

Deppe, A., and Kushnick, G. (2020). Olfactory predator recognition in the brown mouse lemur (Microcebus rufus) in Ranomafana National Park, Madagascar. Am. J. Primatol. 82:e23184. doi: 10.1002/ajp.23184

Deppe, A., Randiramiarisoa, M., and Wright, P. C. (2007). Mammalian predator recognition via olfactory cues in wild brown mouse lemurs (Microcebus rufus). Am. J. Phys. Anthropol. 44:99.

Diamond, J. M. (1975). "Assembly of species communities," in Ecology and Evolution of Communities, eds M. L. Cody and J. M. Diamond (Cambridge: Harvard University Press), 343-444.

Dickman, C. R. (1991). Mechanisms of competition among insectivorous mammals. Oecologia 85, 464-471. doi: 10.1007/bf00323757

Dickman, C. R. (1992). Commensal and mutualistic interaction among terrestrial vertebrates. Trends Ecol. Evol. 7, 194-197. doi: 10.1016/0169-5347(92)90072-j

Eberle, M., and Kappeler, P. M. (2002). Mouse lemurs in space and time: a test of the socioecological model. Behav. Ecol. Sociobiol. 51, 131-139. doi: 10.1007/ s002650100409

Eberle, M., and Kappeler, P. M. (2004). Sex in the dark: determinants and consequences of mixed male mating tactics in Microcebus murinus, a small solitary nocturnal primate. Behav. Ecol. Sociobiol. 57, 77-90. doi: 10.1007/ s00265-004-0826-1

Eberle, M., and Kappeler, P. M. (2006). Family insurance: kin selection and cooperative breeding in a solitary primate (Microcebus murinus). Behav. Ecol. Sociobiol. 60, 582-588. doi: 10.1007/s00265-006-0203-3

Estes, J. A., Terborgh, J., Brashares, J. S., Power, M. E., Berger, J., Bond, W. J., et al. (2011). Trophic downgrading of planet earth. Science 333, 301-306.

Estrada, A., Garber, P. A., Rylands, A. B., Roos, C., Fernandez-Duque, E., Di Fiore, A., et al. (2017). Impending extinction crisis of the world's primates: why primates matter. Sci. Adv. 3:e1600946. doi: 10.1126/sciadv.1600946

Fietz, J. (1999b). Monogamy as a rule rather than exception in nocturnal lemurs: the case of the fat-tailed dwarf lemur, Cheirogaleus medius. Ethology 105, $259-272$.

Fietz, J. (1999a). "Demography and floating males in a population of Cheirogaleus medius," in New Directions in Lemur Studies, eds B. Rakotosamimanana, H. Rasaminanana, J. U. Ganzhorn, and S. M. Goodman (New York, NY: Kluwer Academic/ Plenum), 159-172. doi: 10.1007/978-1-4615-4705-1_9

Fietz, J. (2003). "Primates: “Cheirogaleus, dwarf lemurs or fat-tailed lemurs”," in The Natural History of Madagascar, eds S. M. Goodman and J. P. Benstead (Chicago, IL: University Chicago Press), 1307-1309.

Ganzhorn, J. U. (1987). A possible role of plantations for primate conservation in Madagascar. Am. J. Primatol. 12, 205-215. doi: 10.1002/ajp.1350120208

Ganzhorn, J. U. (1989). Niche separation of seven lemur species in the eastern rainforest of Madagascar. Oecologia 79, 279-286. doi: 10.1007/bf00388489

Ganzhorn, J. U. (1997). Test of Fox's assembly rule for functional groups in lemur communities in Madagascar. J. Zool. 241, 533-542. doi: 10.1111/j.1469-7998. 1997.tb04845.x
Ganzhorn, J. U. (1999). "Body mass, competition and the structure of primate communities," in Primate Communities, eds J. G. Fleagle, C. H. Janson, and K. E. Reed (Cambridge: Cambridge University Press), 141-157. doi: 10.1017/ cbo9780511542381.009

Ganzhorn, J. U., Ganzhorn, A. W., Abraham, J. P., Andriamanarivo, L., and Ramananjatovo, A. (1990). The impact of selective logging on forest structure and tenrec populations in western Madagascar. Oecologia 84, 126-133. doi: 10.1007/bf00665606

Ganzhorn, J. U., and Kappeler, P. M. (1996). Lemurs of the Kirindy forest. Primate Report 46, 257-274.

Ganzhorn, J. U., Malcomber, S., Andrianantoanina, O., and Goodman, S. M. (1997). Habitat characteristics and lemur species richness in Madagascar. Biotropica 29, 331-343. doi: 10.1111/j.1744-7429.1997.tb00434.x

Ganzhorn, J. U., and Schmid, J. (1998). Different population dynamics of Microcebus murinus in primary and secondary deciduous dry forests of madagascar. Int. J. Primatol. 19, 785-796.

Ganzhorn, J. U., Wright, P. C., and Ratsimbazafy, J. (1999). “Primate communities: madagascar," in Primate Communities, eds J. G. Fleagle, C. H. Janson, and K. E. Reed (Cambridge: Cambridge University Press), 75-89. doi: 10.1017/ cbo9780511542381.005

Glasser, J. W. (1979). The role of predation in shaping and maintaining the structure of communities. Am. Nat. 113, 631-641. doi: 10.1086/283422

Grand, T. C., and Dill, L. M. (1999). Predation risk, unequal competitors and the ideal free distribution. Evol. Ecol. Res. 1, 389-409.

Hanski, I., and Henttonen, H. (1996). Predation on competing rodent species: a simple explanation of complex patterns. J. Anim. Ecol. 65, 220-232. doi: $10.2307 / 5725$

Hardin, G. (1960). The competitive exclusion principle. Science 131, 1292-1297. doi: $10.1126 /$ science.131.3409.1292

Harrell, F. E. Jr., and Dupont, C. (2020). Hmisc: Harrell Miscellaneous. R Package Version 4.4-0. https://cran.r-project.org/web/packages/Hmisc/index.html (accessed November 29, 2020).

Herrera, J. P., Wright, P. C., Lauterbur, E., Ratovonjanahary, L., and Taylor, L. L. (2011). The effects of habitat disturbance on lemurs at Ranomafana national park. Madagascar. Int. J. Primatol. 32, 1091-1108. doi: 10.1007/s10764-0119525-8

Heymann, E. W., and Buchanan-Smith, H. M. (2000). The behavioral ecology of mixed-species troops of callitrichine primates. Biol. Rev. 75, 169-190. doi: 10.1111/j.1469-185x.1999.tb00044.x

Hladik, C. M., Charles-Dominique, P., and Petter, J. J. (1980). "Feeding strategies of five nocturnal prosimians in the dry deciduous forest of the west coast of Madagascar," in Nocturnal Malagasy Primates, eds P. Charles-Dominique, H. M. Cooper, A. Hladik, C. M. Hladik, E. Pages, G. F. Pariente, et al. (New York, NY: Academic Press), 41-74. doi: 10.1016/b978-0-12-169350-3.50007-1

Holmes, S. M., Louis, E. E. Jr., and Johnson, S. E. (2019). Range overlap and spatiotemporal relationships of frugivorous lemurs at Kianjavato, Madagascar. Anim. Behav. 155, 53-65. doi: 10.1016/j.anbehav.2019.06.025

Holt, R. D. (1977). Predation, apparent competition, and the structure of prey communities. Theor. Popul. Biol. 12, 197-229. doi: 10.1016/0040-5809(77) 90042-9

Holt, R. D. (1984). Spatial heterogeneity, indirect interactions, and the coexistence of prey species. Am. Nat. 124, 377-406. doi: 10.1086/284280

Holt, R. D., and Lawton, J. H. (1994). The ecological consequences of shared natural enemies. Annu. Rev. Ecol. Syst. 25, 495-520. doi: 10.1146/annurev.es.25.110194. 002431

Holt, R. D., and Polis, G. A. (1997). A theoretical framework for intraguild predation. Am. Nat. 149, 745-764. doi: 10.1086/286018

Hughes, N. K., Korpimäki, E., and Banks, P. B. (2010). The predation risks of interspecific eavesdropping: weasel-vole interactions. Oikos 119, 1210-1216. doi: 10.1111/j.1600-0706.2010.18006.x

Huston, M. A. (1999). Local processes and regional patterns: appropriate scales for understanding variation in the diversity of plants and animals. Oikos 86, 393-401. doi: 10.2307/3546645

Hutchinson, J. M. C., and Waser, P. M. (2007). Use, misuse and extensions of "ideal gas" models of animal encounter. Biol. Rev. 82, 335-359. doi: 10.1111/j.1469185x.2007.00014.x

Irwin, M. T., Raharison, J.-L., and Wright, P. C. (2009). Spatial and temporal variability in predation on rainforest primates: do forest fragmentation and predation act synergistically? Anim. Conserv. 12, 220-230. doi: 10.1111/j.14691795.2009.00243.x 
Irwin, M. T., Wright, P. C., Birkinshaw, C., Fisher, B. L., Gardner, C. J., Glos, J., et al. (2010). Patterns of species change in anthropogenically disturbed forests of Madagascar. Biol. Conserv. 143, 2351-2362. doi: 10.1016/j.biocon.2010.01.023

Jackson, H. B., and Fahrig, L. (2012). What size is a biologically relevant landscape? Landscape Ecol. 27, 929-941. doi: 10.1007/s10980-012-9757-9

Kamilar, J. M. (2009). Environmental and geographic correlates of the taxonomic structure of primate communities. Am. J. Phys. Anthropol. 139, 382-393. doi: 10.1002/ajpa.20993

Kamilar, J. M., Blanco, M. B., and Muldoon, K. M. (2016). "Ecological niche modeling of mouse lemurs (Microcebus spp.) and its implications for their species diversity and biogeography," in The Dwarf and Mouse Lemurs of Madagascar: Biology, Behavior, and Conservation Biogeography of the Cheirogaleidae, eds S. M. Lehman, U. Radespiel, and E. Zimmermann (Cambridge: Cambridge University Press), 449-461. doi: $10.1017 /$ cbo9781139871822.024

Kamilar, J. M., and Guidi, L. M. (2010). The phylogenetic structure of primate communities: variation within and across continents. J. Biogeogr. 37, 801-813. doi: 10.1111/j.1365-2699.2009.02267.x

Kamilar, J. M., and Ledogar, J. A. (2011). Species Co-Occurrence Patterns and Dietary Resource Competition in Primates. Am. J. Phys. Anthropol. 144, 131139. doi: 10.1002/ajpa.21380

Kappel, P., Hohenbrink, S., and Radespiel, U. (2011). Olfactory predator recognition in wild mouse lemurs. Am. J. Primatol. 73, 928-938. doi: 10.1002/ ajp. 20963

Kappeler, P. M. (1997). Intrasexual selection in Mirza coquereli: evidence for scramble competition polygyny in a solitary primate. Behav. Ecol. Sociobiol. 45, 115-127. doi: 10.1007/s002650050371

Kappeler, P. M. (2003). “Mirza coquereli, Coquerel's dwarf lemur," in The Natural History of Madagascar, eds S. M. Goodman and J. P. Benstead (Chicago: University of Chicago Press), 1316-1318.

Kappeler, P. M., and Rasoloarison, R. M. (2003). "Microcebus, mouse lemurs, Tsidy," in The Natural History of Madagascar, eds S. M. Goodman and J. P. Benstead (Chicago, IL: University of Chicago Press), 1310-1315.

Klopfer, P. H. (1977). "Communication in prosimians," in How Animals Communicate, ed. T. A. Sebeok (Bloomington, IN: Indiana University Press), 841-850.

Koivisto, E., Huitu, O., and Korpimäki, E. (2007). Smaller Microtus vole species competitively superior in the absence of predators. Oikos 116, 156-162. doi: 10.1111/j.2006.0030-1299.15254.x

Kotler, B. P., Brown, J. S., and Mitchell, W. A. (1994). The role of predation in shaping the behaviour, morphology and community organisation in desert rodents. Aust. J. Zool. 42, 449-466. doi: 10.1071/zo9940449

Kullberg, C., and Ekman, J. (2000). Does predation maintain tit community diversity? Oikos 89, 41-45. doi: 10.1034/j.1600-0706.2000.890105.x

Lahann, P. (2007). Feeding ecology and seed dispersal of sympatric cheirogaleid lemurs (Microcebus murinus, Cheirogaleus medius, Cheirogaleus major) in the littoral rainforest of south-east Madagascar. J. Zool. 271, 88-98. doi: 10.1111/j. 1469-7998.2006.00222.x

Lahann, P. (2008). Habitat utilization of three sympatric lemur species in a littorial rain forest of Southeastern Madagascar. Int. J. Primatol. 29, 117-134. doi: 10.1007/s10764-007-9138-4

Lawton, J. H., and Hassell, M. P. (1981). Asymmetrical competition in insects. Nature 289, 793-795. doi: 10.1038/289793a0

Lehman, S. M. (2016). "Edge effects on tree dendrometrics, abiotics, and mouse lemur densities in western dry forests in Madagascar," in The Dwarf and Mouse Lemurs of Madagascar: Biology, Behavior, and Conservation Biogeography of the Cheirogaleidae, eds S. M. Lehman, U. Radespiel, and E. Zimmermann (Cambridge: Cambridge University Press), 462-476. doi: 10. 1017/cbo9781139871822.025

Lehman, S. M., Rajaonson, A., and Day, S. (2006c). Lemur responses to edge effects in the Vohibola III classified forest, Madagascar. Am. J. Primatol. 68, 293-299. doi: 10.1002/ajp.20224

Lehman, S. M., Rajaonson, A., and Day, S. (2006a). Edge effects and their influence on lemur density and distribution in Southeast Madagascar. Am. J. Phys. Anthropol. 129, 232-241. doi: 10.1002/ajpa.20241

Lehman, S. M., Rajaonson, A., and Day, S. (2006b). Edge effects on the density of cheirogaleus major. Int. J. Primatol. 27, 1569-1588. doi: 10.1007/s10764-0069099-z
Leibold, M. A., Chase, J. M., Shurin, J. B., and Downing, A. (1997). Species turnover and the regulation of trophic structure. Annu. Rev. Ecol. Evol. Syst. 28, 467-494. doi: 10.1146/annurev.ecolsys.28.1.467

Lennon, J. J. (2000). Red-shifts and red herrings in geographical ecology. Ecography 23, 101-113. doi: 10.1111/j.1600-0587.2000.tb00265.x

Levi, T., Silvius, K. M., Oliveira, L. F. B., Cummings, A. R., and Frangoso, J. M. V. (2013). Competition and facilitation in the capuchin-squirrel monkey relationship. Biotropica 45, 636-643. doi: 10.1111/btp.12046

Levin, S. A. (1992). The problem of pattern and scale in ecology: the Robert H. MacArthur award lecture. Ecology 73, 1943-1967. doi: 10.2307/1941447

Lima, S. L., and Dill, L. M. (1990). Behavioral decisions made under the risk of predation-a review and prospectus. Can. J. Zool. 68, 619-640. doi: 10.1139/ z90-092

López-Gómez, J., and Molina-Meyer, M. (2006). The competitive exclusion principle versus biodiversity through competitive segregation and further adaptation to spatial heterogeneities. Theor. Popul. Biol. 69, 94-109.

Markolf, M., Roos, C., and Kappeler, P. M. (2008). Genetic and demographic consequences of a rapid reduction in population size in a solitary lemur (Mirza coquereli). Open Conserv. Biol. J. 2, 21-29. doi: 10.2174/1874839200802010021

Markolf, M., Schäffler, L., and Kappeler, P. (2020). Microcebus berthae. The IUCN Red List of Threatened Species 2020: e.T41573A115579496. Available online at: https://www.iucnredlist.org/species/41573/115579496 (Accessed July 14, 2020).

McPeek, M. A. (2014). Keystone and intraguild predation, intraspecific density dependence, and a guild of coexisting consumers. Am. Nat. 183, E1-E16.

Norrdahl, K., and Korpimäki, E. (1993). Predation and interspecific competition in two Microtus voles. Oikos 67, 149-158. doi: 10.2307/3545105

Olivieri, G., Zimmermann, E., Randrianambinina, B., Rasoloharijaona, S., Rakotondravony, D., Guschanski, K., et al. (2007). The ever-increasing diversity in mouse lemurs: Three new species in north and northwestern Madagascar. Mol. Phyl. Evol. 4, 309-327. doi: 10.1016/j.ympev.2006.10.026

Paine, R. T. (1966). Food web complexity and species diversity. Am. Nat. 100, 65-75. doi: 10.1086/282400

Paine, R. T. (1969). A note on trophic complexity and community stability. Am. Nat. 103, 61-93.

Pianka, E. R. (1973). The structure of lizzard communities. Annu. Rev. Ecol. Syst. 4, 53-74.

Polis, G. A. (1994). Food webs, trophic cascades and community structure. Austral. Ecol. 19, 121-136. doi: 10.1111/j.1442-9993.1994.tb00475.x

Polis, G. A., and Holt, R. D. (1992). Intraguild predation: the dynamics of complex trophic interactions. Trends Ecol. Evol. 7, 151-155. doi: 10.1016/0169-5347(92) 90208-s

Polis, G. A., Myers, C. A., and Holt, R. D. (1989). The ecology and evolution of intraguild predation. Annu. Rev. Ecol. Syst. 20, 297-330. doi: 10.1146/annurev. es.20.110189.001501

Polis, G. A., and Strong, D. R. (1996). Food web complexity and community dynamics. Am. Nat. 147, 813-846. doi: 10.1086/285880

Porter, L. M. (2001). Dietary differences among sympatric callitrichinae in northern Bolivia: Callimico goeldii, Saguinus fuscicollis and S. labiatus. Int. J. Primatol. 22, 961-992.

R Development Core Team (2018). R: A Language and Environment for Statistical Computing. Vienna: R Foundation for Statistical Computing.

Radespiel, U. (2000). Sociality in the gray mouse lemur (Microcebus murinus) in northwestern Madagascar. Am. J. Primatol. 51, 21-40. doi: 10.1002/(sici)10982345(200005)51:1<21::aid-ajp3>3.0.co;2-c

Radespiel, U. (2016). "Can behavioral ecology help to understand the divergent geographic range sizes of mouse lemurs?" in The Dwarf and Mouse Lemurs of Madagascar: Biology, Behavior, and Conservation Biogeography of the Cheirogaleidae, eds S. M. Lehman, U. Radespiel, and E. Zimmermann (Cambridge: Cambridge University Press), 498-519. doi: 10.1017/cbo9781139871822.027

Radespiel, U., Cepok, S., Zietemann, V., and Zimmermann, E. (1998). Sex-specific usage patterns of sleeping sites in grey mouse lemurs (Microcebus murinus) in Northwestern Madagascar. Am. J. Primatol. 46, 77-84. doi: 10.1002/(sici)10982345(1998)46:1<77::aid-ajp6>3.0.co;2-s

Radespiel, U., Ehresmann, P., and Zimmermann, E. (2003). Species-specific usage of sleeping sites in two sympatric mouse lemur species (Microcebus murinus and M. ravelobensis) in northwestern Madagascar. Am. J. Primatol. 59, 139-151. doi: 10.1002/ajp.10071 
Rakotondranary, S. J., and Ganzhorn, J. U. (2012). Habitat separation of sympatric Microcebus spp. in the dry spiny forest of south-eastern Madagascar. Folia Primatol. 82, 212-223. doi: 10.1159/000334816

Rakotondranary, S. J., Hapke, A., and Ganzhorn, J. U. (2011). Distribution and morphological variation of Microcebus spp. along an environmental gradient in southeastern Madagascar. Int. J. Primatol. 32, 1037-1057. doi: 10.1007/s10764011-9521-z

Rakotondravony, R., and Radespiel, U. (2009). Varying patterns of coexistence of two mouse lemur species (Microcebus ravelobensis and M. murinus) in a heterogeneous landscape. Am. J. Primatol. 71, 928-938. doi: 10.1002/ajp.20732

Rakotonirainy, E. O. (2003). Etude de la prédation entre Mirza coquereli (A. Grandidier, 1867) et Microcebus murinus (J.F. Miller, 1777) dans la forêt de Kirindy, Morondava, Madagascar. Lemur News 8, 29-30.

Randrianandianina, B. N., Andriamahaly, L. R., Harisoa, F. M., and Nicoll, M. E. (2003). "The role of protected areas in the management of the island's biodiversity," in The Natural History of Madagascar, eds S. M. Goodman and J. P. Benstead (Chicago: University of Chicago Press), 1423-1432.

Rasoloarison, R. M., Goodman, S. M., and Ganzhorn, J. U. (2000). Taxonomic revision of mouse lemurs (Microcebus) in the western portions of Madagascar. Int. J. Primatol. 21, 963-1019.

Rendigs, A., Radespiel, U., Wrogemann, D., and Zimmermann, E. (2003). Relationship between microhabitat structure and distribution of mouse lemurs (Microcebus spp.) in Northwestern Madagascar. Int. J. Primatol. 24, 47-64.

Rochette, R., and Grand, T. C. (2004). Mechanisms of species coexistence: a field test of theoretical models using intertidal snails. Oikos 105, 512-524. doi: 10.1111/j.0030-1299.2004.12367.x

Rodman, P. S. (1973). Synecology of bornean primates. I. A test for interspecific interactions in spatial distribution of five species. Am. J. Phys. Anthropol. 38, 655-659. doi: 10.1002/ajpa.1330380283

Rychlik, L., and Zwolak, R. (2005). Behavioural mechanisms of conflict avoidance among shrews. Acta Theriol. 50, 289-308. doi: 10.1007/bf03192627

Schäfler, L. (2012). Determinants of Population Structure in the World's Smallest Primate, Microcebus berthae, Across its Global Range in Menabe Central, Western Madagascar. Ph.D. thesis, Göttingen Centre for Biodiversity and Ecology (GCBE), Georg-August-Universität, Göttingen.

Schäffler, L., and Kappeler, P. M. (2014a). Distribution and abundance of the world's smallest primate, Microcebus berthae, in Central Western Madagascar. Int. J. Primatol. 35, 557-572. doi: 10.1007/s10764-014-9768-2

Schäffler, L., and Kappeler, P. M. (2014b). Distribution and abundance of three cheirogaleid species in Menabe Central, Western Madagascar. Lemur News 18, $38-43$.

Schäffler, L., Kappeler, P. M., and Saborowski, J. (2015). Agent-mediated spatial storage effect in heterogeneous habitat stabilizes competitive mouse lemur coexistence in Menabe Central, Western Madagascar. BMC Ecol. 15:7. doi: 10.1186/s12898-015-0040- 1

Schliehe-Diecks, S., Markolf, M., and Huchard, E. (2010). When big lemurs swallow up small ones: Coquerel's dwarf lemur as a predator of grey mouse lemurs and endemic rodents. Lemur News 15, 13-14.

Schmid, J. (1998). Tree holes used for resting by gray mouse lemurs (Microcebus murinus) in Madagasar: Insulation capacities and energetic consequences. Int. J. Primatol. 19, 797-809.

Schmid, J. (2000). Daily torpor in the gray mouse lemur (Microcebus murinus) in Madagascar: energetic consequences and biological significance. Oecologia 123, 175-183. doi: $10.1007 /$ s004420051003

Schmid, J. (2001). Daily torpor in free-ranging gray mouse lemurs (Microcebus murinus) in Madagascar. Int. J. Primatol. 22, 1021-1031.

Schmid, J., and Kappeler, P. M. (1994). Sympatric mouse lemurs (Microcebus spp.) in Western Madagascar. Folia Primatol. 63, 162-170. doi: 10.1159/000156812

Schmid, J., and Kappeler, P. M. (2005). "Physiological adaptations to seasonality," in Primate Seasonality: Implications for Human Evolution, eds D. K. Brockman and C. P. van Schaik (Cambridge: Cambridge University Press), 129-155. doi: 10.1017/cbo9780511542343.006

Schneider, N., Chikhi, L., Currat, M., and Radespiel, U. (2010). Signals of recent spatial expansions in the grey mouse lemur (Microcebus murinus). BMC Evol. Biol. 10:105. doi: 10.1186/1471-2148-10-105

Schreier, B. M., Harcourt, A. H., Coppeto, S. A., and Somi, M. F. (2009). Interspecific competition and niche separation in primates: a global analysis. Biotropica 41, 283-291. doi: 10.1111/j.1744-7429.2008.00486.x
Schwab, D., and Ganzhorn, J. U. (2004). Distribution, population structure and habitat use of Microcebus berthae compared to those of other sympatric Cheirogaleids. Int. J. Primatol. 25, 307-330. doi: 10.1023/b:ijop.0000019154. 17401.90

Sfenthourakis, S., Tzanatos, E., and Giokas, S. (2006). Species co-occurrence: the case of congeneric species and a causal approach to patterns of species association. Glob. Ecol. 15, 39-49. doi: 10.1111/j.1466-822x.2005.00192.x

Singh, M., Roy, K., and Singh, M. (2011). Resource partitioning in sympatric langurs and macaques in tropical rainforests of the Central Western Ghats, South India. Am. J. Primatol. 73, 335-346. doi: 10.1002/ajp.20900

Smith, A. P., Horning, N., and Moore, D. (1997). Regional biodiversity planning and lemur conservation with GIS in Western Madagascar. Conserv. Biol. 11, 498-512. doi: 10.1046/j.1523-1739.1997.95283.x

Sorg, J. P., Ganzhorn, J. U., and Kappeler, P. M. (2003). "Forestry and research in the Kirindy Forest/ Centre de Formation Professionnelle Forestière"," in The Natural History of Madagascar, eds S. M. Goodman and J. P. Benstead (Chicago, IL: University of Chicago Press), 1512-1519.

Sorg, J. P., and Rohner, U. (1996). "Climate and tree phenology of the dry deciduous forest of the Kirindy Forest," in Ecology and Economy of a Tropical Dry Forest in Madagascar, eds J. U. Ganzhorn and J.-P. Sorg (Göttingen: DPZ Primate Report), 57-80.

Stachowicz, J. J. (2001). Mutualism, facilitation, and the structure of ecological communities. Bioscience 51, 235-246. doi: 10.1641/0006-3568(2001)051[0235: mfatso]2.0.co;2

Stanford, C. B. (1995). The influence of chimpanzee predation on group size and anti-predator behaviour in red colobus monkeys. Anim. Behav. 49, 577-587. doi: 10.1016/0003-3472(95)90033-0

Steffens, T. S., and Lehman, S. M. (2016). "Factors determining Microcebus abundance in a fragmented landscape in Ankarafantsika National Park, Madagascar," in The Dwarf and Mouse Lemurs of Madagascar: Biology, Behavior, and Conservation Biogeography of the Cheirogaleidae, eds S. M. Lehman, U. Radespiel, and E. Zimmermann (Cambridge: Cambridge University Press), 477-497. doi: 10.1017/cbo9781139871822.026

Steffens, T. S., and Lehman, S. M. (2018). Lemur species-specific metapopulation responses to habitat loss and fragmentation. PLoS One 13:e0195791. doi: 10. 1371/journal.pone.0195791

Stensland, E., Angerbjörn, A., and Berggren, P. (2003). Mixed species groups in mammals. Mammal Rev. 33, 205-223. doi: 10.1046/j.1365-2907.2003.00022.x

Sterling, E. J., Nguyen, N., and Fashing, P. J. (2000). Spatial patterning in nocturnal prosimians: A review of methods and relevance to studies of sociality. Am. J. Primatol. 51, 3-19. doi: 10.1002/(sici) 1098-2345(200005)51:1<3::aid-ajp2>3.0. co; $2-d$

Stokstad, E. (2009). On the origin of ecological structure. Science 326, 33-36. doi: 10.1126/science.326_33

Strauss, S. Y. (1991). Indirect effects in community ecology: their definition, study and importance. Trends Ecol. Evol. 6, 206-210. doi: 10.1016/0169-5347(91) 90023-q

Sundell, J., Eccard, J. A., and Ylönen, H. (2003). Predation rate, prey preference and predator switching: experiments on voles and weasels. Oikos 101, 615-623. doi: $10.1034 / j .1600-0706.2003 .12264 . x$

Sündermann, D., Scheumann, M., and Zimmermann, E. (2008). Olfactory predator recognition in predator-naïve gray mouse lemurs (Microcebus murinus). J. Comp. Psychol. 122, 146-155. doi: 10.1037/0735-7036.122.2.146

Teelen, S. (2007a). Influence of chimpanzee predation on associations between red colobus and red-tailed monkeys at Ngogo, Kibale National Park, Uganda. Int. J. Primatol. 28, 593-606. doi: 10.1007/s10764-007-9140-x

Teelen, S. (2007b). Primate abundance along five transect lines at Ngogo, Kibale National Park, Uganda. Am. J. Primatol. 69, 1030-1044. doi: 10.1002/ajp.20417

Teelen, S. (2008). Influence of chimpanzee predation on the red colobus population at Ngogo, Kibale National Park, Uganda. Primates 49, 41-49. doi: 10.1007/ s10329-007-0062-1

Terborgh, J. (1990). Mixed flocks and polyspecific associations: costs and benefits of mixed groups to birds and monkeys. Am. J. Primatol. 21, 87-100. doi: 10.1002/ajp.1350210203

Thorén, S., Carstens, K. F., Schwochow, D., and Radespiel, U. (2016). "Your food, my food: patterns of resource use in two sympatric mouse lemur species," in The Dwarf and Mouse Lemurs of Madagascar: Biology, Behavior, and Conservation Biogeography of the Cheirogaleidae, eds S. M. Lehman, U. Radespiel, and E. 
Zimmermann (Cambridge: Cambridge University Press), 305-316. doi: 10. $1017 /$ cbo9781139871822.016

Thorén, S., Linnenbrink, M., and Radespiel, U. (2011a). Different competitive potential in two coexisting mouse lemur species in northwestern Madagascar. Am. J. Phys. Anthropol. 145, 156-162. doi: 10.1002/ajpa.21516

Thorén, S., Quietzsch, F., Schwochow, D., Sehen, L., Meusel, C., Meares, K., et al. (2011b). Seasonal changes in feeding ecology and activity patterns of two sympatric mouse lemur species, the gray mouse lemur (Microcebus murinus) and the golden-brown mouse lemur (M. ravelobensis), in northwestern Madagascar. Int. J. Primatol. 32, 566-586. doi: 10.1007/s10764-010-9488- 1

Tilman, D. (1994). Competition and biodiversity in spatially structured habitats. Ecology 75, 2-16. doi: 10.2307/1939377

Tilman, D., May, R. M., Lehman, C. L., and Nowak, M. A. (1994). Habitat destruction and the extinction debt. Nature 371, 65-66. doi: 10.1038/371065a0

Tilson, R. L., and Tenaza, R. R. (1982). Interspecific spacing between gibbons (Hylobates klossii) and langurs (Presbytis potenziani) on Siberut Island, Indonesia. Am. J. Primatol. 2, 355-361. doi: 10.1002/ajp.1350020404

Ulrich, W., and Gotelli, N. J. (2010). Null model analysis of species associations using abundance data. Ecology 91, 3384-3397. doi: 10.1890/09-2157.1

Vasey, N. (2000). Niche separation in Varecia variegata rubra and Eulemur fulvus albifrons: I. interspecific patterns. Am. J. Phys. Anthropol. 112, 411-431. doi: 10.1002/1096-8644(200007)112:3<411::aid-ajpa10>3.0.co;2-r

Wahungu, G. M. (1998). Diet and habitat overlap in two sympatric primate species, the Tana crested mangabey Cercocebus galeritus and yellow baboon Papio cynocephalus. Afr. J. Ecol. 36, 159-173. doi: 10.1046/j.1365-2028.1998. 00120.x

Walsh, M. R. (2013). The evolutionary consequences of indirect effects. Trends Ecol. Evol. 28, 23-29. doi: 10.1016/j.tree.2012.08.006

Weisrock, D. W., Rasoloarison, R. M., Fiorentino, I., Ralison, J. M., Goodman, S. M., Kappeler, P. M., et al. (2010). Delimiting species without nuclear monophyly in Madagascar's mouse lemurs. PLoS One 5:e9883. doi: 10.1371/ journal.pone. 0009883

Willems, E. P., and Hill, R. A. (2009). Predator-specific landscapes of fear and resource distribution: Effects on spatial range use. Ecology 90, 546-555. doi: 10.1890/08-0765.1

Wilmé, L., Goodman, S. M., and Ganzhorn, J. U. (2006). Biogeographic evolution of Madagascar's microendemic biota. Science 312, 1063-1065. doi: 10.1126/ science. 1122806

Wimmer, B., Tautz, D., and Kappeler, P. M. (2002). The genetic population structure of the gray mouse lemur (Microcebus murinus), a basal primate from Madagascar. Behav. Ecol. Sociobiol. 52, 166-175. doi: 10.1007/s00265-0020497-8

Wootton, J. T. (1994). The nature and consequences of indirect effects in ecological communities. Annu. Rev. Ecol. Syst. 25, 443-466. doi: 10.1146/annurev.es.25. 110194.002303

Yoder, A. D., Rasoloarison, R. M., Goodman, S. M., Irwin, J. A., Atsalis, S., Ravosa, M. J., et al. (2000). Remarkable species diversity in Malagasy mouse lemurs (Primates, Microcebus). Proc. Natl. Acad. Sci. U.S.A. 97, 11325-11330. doi: $10.1073 /$ pnas. 200121897

Conflict of Interest: The authors declare that the research was conducted in the absence of any commercial or financial relationships that could be construed as a potential conflict of interest.

Copyright (c) 2021 Schäfler, Kappeler and Halley. This is an open-access article distributed under the terms of the Creative Commons Attribution License (CC BY). The use, distribution or reproduction in other forums is permitted, provided the original author(s) and the copyright owner(s) are credited and that the original publication in this journal is cited, in accordance with accepted academic practice. No use, distribution or reproduction is permitted which does not comply with these terms. 